\title{
Airborne instruments to measure atmospheric aerosol particles, clouds and radiation: A cook's tour of mature and emerging technology
}

D. Baumgardner $^{\text {a, } *}$, J.L. Brenguier ${ }^{\text {b }}$, A. Bucholtz ${ }^{\text {c }}$, H. Coe ${ }^{\text {d }}$, P. DeMott ${ }^{\text {e }}$, T.J. Garrett ${ }^{\text {f }}$, J.F. Gayet ${ }^{g}$, M. Hermann ${ }^{\text {h }}$, A. Heymsfield ${ }^{\mathrm{i}}$, A. Korolev ${ }^{\mathrm{j}}$, M. Krämer ${ }^{\mathrm{k}}$, A. Petzold ${ }^{\mathrm{l}}$, W. Strapp ${ }^{\text {m }}$, P. Pilewskie ${ }^{\mathrm{n}}$, J. Taylor ${ }^{\circ}$, C. Twohy ${ }^{\mathrm{p}}$, M. Wendisch ${ }^{\mathrm{q}}$, W. Bachalo ${ }^{\mathrm{r}}$, P. Chuang ${ }^{\mathrm{s}}$

a Universidad Nacional Autonoma de Mexico, Centro de Ciencias de la Atmosfera, Ciudad Universitaria, Mexico City 04510, Mexico

b CNRM, France

c Naval Research Laboratory, Monterey, CA 93901, USA

d University of Manchester, Manchester, England, United Kingdom

e Colorado State University, Ft. Collins, CO, USA

${ }^{\mathrm{f}}$ University of Utah, Department of Atmospheric Sciences, Salt Lake City, UT 84103, USA

g LaMP, Clermont Ferrand, France

h Leibniz Institute for Tropospheric Research, 04318 Leipzig, Germany

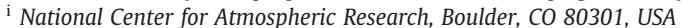

j Environment Canada, Toronto, Canada

k Forschungszentrum Jülich, Institut für Energie- und Klimaforschung Stratosphäre (IEK-7) 52425 Jülich, Germany

${ }^{1}$ DLR, Oberpfaffenhofen, Germany

m Environment Canada, Toronto, Canada

${ }^{\mathrm{n}}$ University of Colorado, Boulder, CO, USA

${ }^{\circ}$ United Kingdom Meteorological Office, Exeter, England, United Kingdom

p Oregon State University, Corvallis, OR, 97128, USA

q Universität Leipzig, Leipziger Institut für Meteorologie (LIM), Stephanstr. 3. 04103 Leipzig, Germany

${ }^{\mathrm{r}}$ Artium, CA, USA

${ }^{\mathrm{s}}$ University of California Santa Cruz, CA, USA

\section{A R T I C L E I N F O}

\section{Article history:}

Received 15 October 2010

Received in revised form 19 June 2011

Accepted 27 June 2011

\section{Keywords:}

In situ airborne measurements

Instrumentation

Aerosol particles

Cloud microphysics

Solar radiation

\begin{abstract}
A B S T R A C T
An overview is presented of airborne systems for in situ measurements of aerosol particles, clouds and radiation that are currently in use on research aircraft around the world. Description of the technology is at a level sufficient for introducing the basic principles of operation and an extensive list of references for further reading is given. A number of newer instruments that implement emerging technology are described and the review concludes with a description of some of the most important measurement challenges that remain. This overview is a synthesis of material from a reference book that is currently in preparation and that will be published in 2012 by Wiley.
\end{abstract} (c) 2011 Elsevier B.V. All rights reserved.

\footnotetext{
* Corresponding author.

E-mail addresses: darrel.baumgardner@gmail.com (D. Baumgardner), anthony.bucholtz@nrlmry.navy.mil (A. Bucholtz), Tim.Garrett@utah.edu (T.J. Garrett), hermann@tropos.de (M. Hermann), heyms1@ucar.edu (A. Heymsfield), m.kraemer@fz-juelich.de (M. Krämer), twohy@coas.oregonstate.edu (C. Twohy), m.wendisch@uni-leipzig.de (M. Wendisch).
} 


\section{Contents}

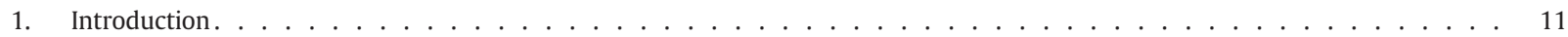

2. Aerosol measurement techniques. . . . . . . . . . . . . . . . . . . . . . . . . . . . . 12

2.1. Aerosol number concentrations . . . . . . . . . . . . . . . . . . . . . . . . . . . . . . . . . 12

2.2. Aerosol optical properties . . . . . . . . . . . . . . . . . . . . . . . . . . . . . . 12

2.3. Chemical properties. . . . . . . . . . . . . . . . . . . . . . . . . 13

2.3.1. Bulk aerosol collection and analysis . . . . . . . . . . . . . . . . . . . . . . . . . 13

2.3.2. Mass spectrometric methods . . . . . . . . . . . . . . . . . . . . . . . . . . . 13

2.3.3. Single particle soot photometry . . . . . . . . . . . . . . . . . . . . . . . . . . . 14

2.3.4. Cloud condensation and ice nuclei. . . . . . . . . . . . . . . . . . . . . . . . . . . 14

2.4. Emerging technology . . . . . . . . . . . . . . . . . . . . . . . . . . . . . 14

2.4.1. New approach for IN detection . . . . . . . . . . . . . . . . . . . . . . . . 14

2.4.2. Measurement of particle morphology . . . . . . . . . . . . . . . . . . . . . . . . . . . . 14

3. Cloud measurement techniques. . . . . . . . . . . . . . . . . . . . . . . . . 15

3.1. Number concentrations . . . . . . . . . . . . . . . . . . . . . . . . . . . . . . . . . . . . . 15

3.1.1. Single particle impaction techniques. . . . . . . . . . . . . . . . . . . . . . . 15

3.1.2. Single particle light scattering techniques . . . . . . . . . . . . . . . . . . . . . . . . . 15

3.1.3. Single particle imaging techniques. . . . . . . . . . . . . . . . . . . . . . . . 17

3.2. Mass concentration . . . . . . . . . . . . . . . . . . . . . . . . . . . 17

3.2.1. Heated element techniques . . . . . . . . . . . . . . . . . . . . . . . . . . . . . 18

3.2.2. Inlet-based evaporating systems. . . . . . . . . . . . . . . . . . . . . . . . . . . . 18

3.2.3. Other sensing techniques for LWC . . . . . . . . . . . . . . . . . . . . . . . . . . . . 19

3.3. Optical properties. . . . . . . . . . . . . . . . . . . . . . . . . . . . . 19

3.3.1. The cloud extinction probe . . . . . . . . . . . . . . . . . . . . . . . . . . . . . . 19

3.3.2. The polar nephelometer . . . . . . . . . . . . . . . . . . . . . . . . . . . 20

3.3.3. Cloud integrating nephelometer. . . . . . . . . . . . . . . . . . . . . . 20

3.4. Emerging technology . . . . . . . . . . . . . . . . . . . . . . . . . . 21

3.4.1. Phase Doppler interferometry . . . . . . . . . . . . . . . . . . . . . . . 21

3.4.2. Holography . . . . . . . . . . . . . . . . . . . . . . . . . . . . . 21

3.4.3. Distinguishing Ice crystals from water droplets. . . . . . . . . . . . . . . . . . . . . . . . . . . . . . . . . . . . . . . . .

4. Radiation measurement techniques . . . . . . . . . . . . . . . . . . . . . . . . . . . . 22

4.1. Solar spectral radiometry . . . . . . . . . . . . . . . . . . . . . . . . . . . . 22

4.2. Actinic flux density measurement . . . . . . . . . . . . . . . . . . . . . . . . . . . . . . 22

4.3. Stabilized radiometer platforms . . . . . . . . . . . . . . . . . . . . . . . . . . . . . . 23

4.4. Future outlook for radiometery . . . . . . . . . . . . . . . . . . . . . . . . . . . . . 23

5. Measurement challenges . . . . . . . . . . . . . . . . . . . . . . . . . . . . . . . . . . . . . 24

5.1. Anisokinetic sampling . . . . . . . . . . . . . . . . . . . . . . . . . . . . . . . 24

5.2. Cloud particle breakup . . . . . . . . . . . . . . . . . . . . . . . . . . . . . . . . . . . . . . . 24

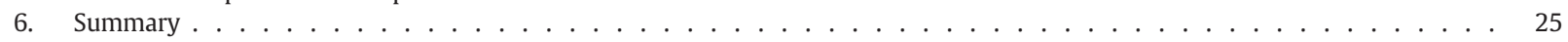

Disclaimer. . . . . . . . . . . . . . . . . . . . . . . . . . . . . 25

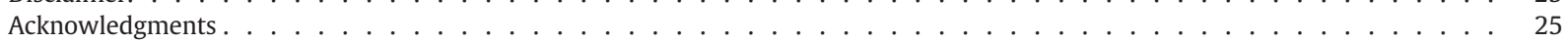

References . . . . . . . . . . . . . . . . . . . . . . . . . . . 26

\section{Introduction}

The fact that global climate is modified as a result of the complex interactions between solar radiation and atmospheric particles is undisputed, but the magnitude and sign (warming versus cooling) of the effects remain a major point of debate. Numerous models have been developed that explore the processes by which aerosol particles interact directly with solar and terrestrial radiation and how some of these particles subsequently form cloud droplets or ice crystals, further enhancing such interactions. The results from these models are often at odds with one another, largely due to differences in how the aerosol and cloud properties are represented in the simulations, differences that are partially attributable to lack of detailed measurements of these properties over a broad enough range of conditions.

The use of satellites, whose measurement capabilities continue to expand with respect to their sophistication, resolution and coverage, has made a significant improvement in the fidelity of the models as the model products can be validated and data assimilated. The advances in satellite technology and associated analysis algorithms have been accompanied by validation programs that compare in situ measurements with satellite products. These types of validation studies are invaluable and many more are needed with even more sophisticated airborne instruments on platforms that can cover larger spatial ranges over many pixels of satellite resolution.

Here we give a broad overview of the sensors that are currently being used worldwide on research aircraft for investigating basic atmospheric processes and acquiring information that expands the data bases of aerosol, clouds and radiation, sources of data that are essential for validating model products and satellite retrieval algorithms. Our objective is to provide sufficient information on operating principles, limitations and uncertainties at a level of detail that will provide 
graduate students, technical personnel and scientists with enough information to make educated decisions about instrument selection or data interpretation. A comprehensive list of references is also provided for those wishing more detailed information on particular measurement systems. This review is extracted from a book on airborne atmospheric measurements currently in preparation.

\section{Aerosol measurement techniques}

The development of airborne aerosol observations was catalyzed by the development of improved optical methods for cloud and aerosol particle sizing, like that of the Forward Scattering Spectrometer Probes (FSSP). Additional advances in airborne, aerosol measurements came with the development of sensitive methods for measuring aerosol optical properties, on-line aerosol chemical composition and the cloud-forming potential of particles. The instrumentation can be classified with respect to the aerosol characteristics they are specifically designed to measure: 1 ) total number and mass concentration, 2) size distributions, 3) optical properties and 4) chemical composition, where chemical composition includes the cloud-forming properties.

Instruments that can measure aerosol properties in ground based applications can usually be adapted for operation inside an aircraft. The challenge is to bring the particles from the ambient air outside the aircraft to the instrument's sampling chamber in the cabin without altering the aerosol properties. This issue was the topic of an international workshop (Wendisch et al., 2004) that addressed problems of inlet losses, operation of instruments in pressurized aircraft and anisokinetic sampling, to name just a few. A number of low particle loss inlets are now in use that have allowed technology, originally designed for ground based measurements, to be implemented inside the aircraft (e.g. Blomquist et al., 2001; Wilson et al., 2004; Huebert et al., 2004).

Adapting a ground based instrument for operation outside the aircraft, attached to the fuselage or wing, is more challenging than installation in the cabin due to the many environmental factors that affect the measurement, e.g. extremes in temperature $\left(-80{ }^{\circ} \mathrm{C}\right.$ to $\left.+40{ }^{\circ} \mathrm{C}\right)$, pressure ( $1000 \mathrm{mb}$ to $50 \mathrm{mb}$ ), humidity (>100\%), air velocities (50 to $250 \mathrm{~ms}^{-1}$ ), vibration, turbulence, air flow distortion, icing and bird strikes, to name some of the factors that face the instrument designer. The majority of the aerosol instruments in use today are operated inside the aircraft cabin with the exception of the optical spectrometers discussed below.

\subsection{Aerosol number concentrations}

The total number concentration of aerosol particles is typically measured with Condensation Particle Counters (CPCs) mounted in the cabin and sampling from an inlet. In general, an airborne CPC operates very similar to standard ground-based CPCs. In the continuous flow diffusion CPC, which is the most frequently used today for airborne operation (Wilson et al., 1983; Weigel et al., 2009) ambient aerosol enters via an inlet and is then exposed to a supersaturated vapor of a working fluid that condenses rapidly on the particles that subsequently grow to sizes of several micrometers before traversing a laser beam where they scatter light that is detected by a photo diode. The individual particles are counted and for a known flow rate the aerosol number concentration can be calculated. Typically, a CPC detects particles in the size range between a few nanometers up to a few micrometers, the range of diameters commonly encountered in the atmosphere. A comprehensive review of the operating principles and the historical development of CPCs in general are given by McMurry (2000).

The airborne, in situ instruments, the only ones that mount on the exterior of the aircraft and that are presently deployed to measure particle number concentrations as a function of size, are the Passive Cavity Aerosol Spectrometer Probe (PCASP), the Ultrahigh Sensitivity Aerosol Spectrometer (UHSAS) and the Model 300 FSSP. The FSSP-300 and PCASP measure in the size range from 0.3 to $20 \mu \mathrm{m}$ and 0.12 to $10 \mu \mathrm{m}$, respectively and the UHSAS measure from $0.06 \mu \mathrm{m}$ to $1.0 \mu \mathrm{m}$.

These instruments measure the intensity of light scattered from individual particles that pass through a focused laser beam. The collected light is proportional to the particle size and is predicted theoretically when the shape and refractive index of a particle is known, as well as the wavelength of the incident light (Mie, 1908). The FSSP-300 is described in detail by Baumgardner et al. (1992) and the PCASP is described by Strapp et al. (1992) and Liu et al. (1992). There are two major differences between the FSSP-300 and the other two spectrometers. The FSSP-300 measures forward scattered light $\left(4-12^{\circ}\right)$ and the PCASP and UHSAS collect side scattered light (approximately $30-120^{\circ}$ ). The measurement by the FSSP-300 is made in non-restricted flow whereas the PCASP and UHSAS require an anisokinetic flow system that decelerates the flow before the measurement is made.

\subsection{Aerosol optical properties}

The light scattering and absorption coefficients are the optical properties from which extinction, optical depth and single scattering albedo are derived. Integrating nephelometry is the technique (Beuttell and Brewer, 1949) based on the geometrical integration of the angular distribution of the light scattered by gas molecules and aerosol particles in an enclosed volume. The incident light is provided by a nearlambertian light source, generally an array of light-emitting diodes (LEDs), flash lamp or quartz-halogen lamp, and measured by a photomultiplier detector, placed at $90^{\circ}$ with respect to the lamp position to avoid stray light detection. This technique has been implemented in a number of commercially available instruments (Anderson and Ogren, 1998; Heintzenberg et al., 2006). An alternative approach is to use a sensor that utilizes reciprocal nephelometry (Rahman et al., 2006). A 'reciprocal' nephelometer is different from a 'standard' nephelometer in that the light source and detector positions are reversed. In a standard nephelometer with a broad-band incandescent light source, optical filters are used to select scattered light in a wavelength band. With a reciprocal nephelometer, the laser bandwidth is much narrower and more precisely defined making the instrument response easier to quantify. The reciprocal nephelometer has been integrated in the Photoacoustic Absorption Spectrometer (PAS, Arnott et al., 1999) discussed below. 
The instruments that determine the absorption coefficient do so by measuring the attenuation of light transmitted through an aerosol laden filter or, alternatively, by employing a photoacoustic technique whereby the aerosol absorption is related to the heating of the particles and the energy they transfer to the surrounding air.

A limitation of the filter technique is that various corrections are needed, among them a correction to account for light scattering by the particles on the filter surface. The multi-angle absorption photometer (MAAP) addresses this problem by simultaneously measuring attenuation and light scattering from the aerosols on the filter and then applies a radiative transfer scheme for data interpretation which includes the treatment of light scattering (Petzold and Schönlinner, 2004; Petzold et al., 2005).

Photoacoustic spectrometers have much faster response times than filter based instruments and are well suited for airborne applications (Arnott et al., 1999; Moosmüller et al., 2009). Particles contained in a cylindrical cavity are illuminated by amplitude modulated laser radiation. Part of the incoming intensity is scattered or transmitted and the remaining fraction is absorbed either by the light absorbing particles and/or by the surrounding gas. The absorbed radiation generates heating and an increase in pressure that is detected with a sensitive microphone. The relationship between pressure and light absorption is established through calibration.

\subsection{Chemical properties}

The composition of atmospheric aerosol has been measured from aircraft using a range of online methods. One approach is to collect the aerosol and analyze it in real-time onboard the aircraft. Another approach uses real-time, online detection with mass spectrometric methods. The two most commonly used methods are single particle detection and ablation, based on laser methods, and thermal vaporization techniques which largely provide information on particle ensembles. Online aerosol composition measurements were pioneered in the late 1990s (Murphy et al., 1998; Thomson et al., 2000). In addition to the above methods for investigation, some online instruments have been designed to measure a single chemical component of atmospheric particles; most notable of these is the single particle incandescence method for refractory black carbon ( $\mathrm{rBC})$.

\subsubsection{Bulk aerosol collection and analysis}

One of the first measurements of this type was a chamber in which a droplet mist is created by accelerating ambient air with a nozzle through which ultra-pure water is aspirated (Scheuer et al., 2003). The water with the sample is injected into an ion chromatograph for analysis of dissolved ionic species. This approach was used to study aerosol composition during airborne studies across the Pacific region (Dibb et al., 2002, 2003) and provided some of the first measurements of vertical profiles of submicron particle component mass.

The Particle-Into-liquid Sampler (PILS), initially developed by Weber et al. (2001), and first used on an aircraft by Orsini et al. (2003), uses droplets to dissolve aerosol components and deliver them for analysis in real time; however, the instrument differs from the mist chamber in that the ambient, particle-laden flow from outside the aircraft is mixed with a turbulent flow of steam held at $100{ }^{\circ} \mathrm{C}$. The cooling of the steam when mixed with ambient air causes a large supersaturation in the sample flow and the ambient particles will rapidly grow to super-micron sized solution droplets that are inertially separated from the gas flow and impacted onto a vertical quartz surface via a single jet nozzle at the end of the sampler that focuses the droplets. A filtered flow of deionized water removes the solution sample into a liquid flow to a detection system like an ion chromatograph.

\subsubsection{Mass spectrometric methods}

Two main types of aerosol mass spectrometry have been developed to date for aircraft applications. One approach uses laser based methods to ablate and ionize the particles before mass spectrometric detection. This method is able to sample single particles with a wide range of compositions. The second technique uses thermal volatilization of the particles. This method performs a separate ionization process using electron impact on the volatilized gaseous material and hence can deliver mass quantification; however, due to the relatively low volatilization temperatures, the refractory components cannot be detected.

As described in an excellent review by Murphy (2007) in single particle mass spectrometers the particles are entrained into a vacuum through an inlet, which also acts to focus the particles through the laser detection region. Once in the vacuum region, the particle size is detected by optical methods, either by optical scattering using a continuous laser or by aerodynamic sizing. These sizing systems are used to trigger a laser pulse with sufficient energy to ablate the particle and ionize the fragments that are then transmitted to a mass spectrometer.

The first mass spectrometer to be flown on an aircraft (Thomson et al., 2000) was the Particle Analysis by Laser Mass Spectrometer (PALMS) instrument flown on the NASA WB-57 aircraft. The instrument has been used to establish the presence of meteoritic material in the upper troposphere and lower stratosphere and to establish the presence of a large fraction of organic particulate in the upper troposphere (Murphy et al., 1998; Cziczo et al., 2001; Murphy et al., 2006; Froyd et al., 2009).

A new design for single particle, laser ablation, aerosol mass spectrometry uses a $\mathrm{Z}$ shaped mass spectrometer to maximize the mass resolution in as small a volume as possible (Pratt et al., 2009b). This instrument has most recently been coupled to a counter flow virtual impactor (CVI) to show that biological particles are efficient ice nuclei (Pratt et al., 2009a).

The only instrument that has operated on aircraft platforms using thermal methods to volatilize particles before subsequent mass spectrometric selection is the AMS, first developed by Jayne et al. (2000) and described in detailed by Canagaratna et al. (2007). An AMS fitted with time of flight (TOF) mass spectrometers can deliver full mass spectral information as a function of particle size while alternating between mass spectrometric and TOF modes as the sensitivity of the former is a factor 50 larger than the latter. The first airborne measurements using an AMS were made with a quadrupole system during the ACE-ASIA study (Bahreini et al., 2003). Most aircraft making AMS measurements now use either the C-shaped TOFAMS (e.g. Morgan et al., 2009) or the 
high resolution AMS (e.g. DeCarlo et al., 2008), which typically have sensitivities 30 and 10 times greater than the quadrupole systems.

\subsubsection{Single particle soot photometry}

Previous measurements of black carbon (BC) from aircraft have been made either by offline analysis of filters or by deriving it from the particle light absorption measurements described above. The former technique has poor time resolution and the latter is dependent on a highly variable relationship between $\mathrm{BC}$ mass and absorption. An online approach to the measurement of refractory $\mathrm{BC}(\mathrm{rBC})$ mass and its size distribution, the single particle soot photometer (SP2, Stephens et al., 2003) was first deployed on aircraft for investigating the $\mathrm{BC}$ component of aerosols in the Arctic lower stratospheric, using the NASA DC-8 (Baumgardner et al., 2004).

As described by Schwarz et al. (2006) the SP2 uses light scattering to size particles within the laser cavity of a Nd:YAG laser $(1064 \mathrm{~nm})$ while particles that absorb light at the wavelength of the laser, e.g., those that contain rBC, are rapidly heated to incandescence. The black body radiation emitted by the incandescence is proportional to the mass of $\mathrm{rBC}$ within the particle. The mass is derived from the amplitude of the incandescence signal by a calibration using rBC particles of a known size. Aircraft studies using the SP2 have been undertaken to investigate the abundance and source of $\mathrm{rBC}$ in the Arctic upper troposphere and lower stratosphere (Hendricks et al., 2004), investigate the evolution of urban plumes (Moteki et al., 2007) and provide measurements of the vertical distribution of rBC in global models (Schwarz et al., 2006).

\subsubsection{Cloud condensation and ice nuclei}

Airborne measurements of cloud condensation nuclei (CCN) are made with static thermal gradient diffusion chambers (i.e., Squires and Twomey, 1966; Twomey and Wojciechowski, 1969) or continuous flow techniques (Sinnerwalla and Alofs, 1973; Hudson and Squires, 1976; Fukuta and Saxena, 1979). Both techniques create a controlled, supersaturated (S) environment in which CCN will grow. Static chambers use batch processing of the light scattering signal from the activated (growing by condensation) droplets (e.g., Lala and Juisto, 1977; Snider and Brenguier, 2000) or from counting droplets in photographs (e.g., Delene et al., 1998). The static chamber of Snider et al. (2003) has been optimized for airborne measurements and can obtain a four-point spectrum of concentration versus $S$ in $140 \mathrm{~s}$.

The continuous flow technique was developed to achieve higher temporal resolution for aircraft (Sinnerwalla and Alofs, 1973; Hudson and Squires, 1976; Fukuta and Saxena, 1979). Hudson (1989) extended the continuous-flow technique to develop a CCN spectrometer with an S range from 0.01 to $1 \%$. Roberts and Nenes (2005) exploited differences in mass and heat diffusion with a cylindrical, continuous-flow, thermalgradient $\mathrm{CCN}$ instrument that generates a constant $\mathrm{S}$ along the streamwise axis. CCN spectra in this device can be obtained in airborne applications by changing the flow rate (Moore and Nenes, 2009). A thorough review and assessment of the performance of various CCN instruments is discussed in greater detail by Nenes et al. (2001) and Rose et al. (2008).
Direct measurements at $\mathrm{S}$ below $0.1 \%$ remain a challenge as most CCN instruments are limited to larger $S$ due to short growth times.

The techniques that are employed on aircraft to measure ice nuclei (IN) are 1) cloud chambers, 2) mixing devices, 3) continuous flow diffusion chambers, 4) contact freezing methods or 5) the capturing of particles for offline analyses or processing (DeMott, in press). The technique most frequently used in modern application is the continuous flow diffusion chamber (CFDC) that is designed to allow cloud and ice formation under controlled temperature and humidity conditions during continuous sampling. Ice and water supersaturations are created within the space between two ice-coated walls held at different temperatures (e.g., Rogers, 1988; Rogers et al., 2001; Super, in press). Continuous flow allows continuous and near real-time measurements of a wide dynamic range of IN number concentrations, as well as ease of interfacing with methods for collecting activated IN for chemical analyses via electron microscopy (e.g., Kreidenweis et al., 1998) or single particle mass spectrometry (Cziczo et al., 2003). Designs differ only in the applied geometry/ orientation and the means for detecting ice formation. The actual detection of activated IN is performed using systems to detect the growth of activated ice crystals that are larger than droplets or to detect the ice phase via scattering or depolarization properties.

\subsection{Emerging technology}

\subsubsection{New approach for IN detection}

A new device using mixing to generate controlled $\mathrm{S}$ at supercooled temperatures for IN activation has been described by Bundke et al. (2008). In the Fast Ice Nucleus CHamber (FINCH) the supersaturation is produced from the turbulent mixing of cold dry air with warm humidified air in a closed loop system. Ice particles grown to sizes above $4 \mu \mathrm{m}$ during about $10 \mathrm{~s}$ residence time are discriminated from droplets by their individual circular depolarization properties and counted in an optical detector. The biological fraction is also measured in an additional fluorescence channel (Bundke et al., 2010). Potential advantages of this instrument are: a) a high sample flow (up to 10 LPM) for improved counting statistics at low IN concentrations; b) demonstrated use of active monitoring of $\mathrm{RH}$ and $\mathrm{T}$ in the ice activation region; and c) capability for rapid variation of S and T through varying the flow rates of the different particle-free gas-flows. Possible limitations relate to the complex depolarization and frost point measurements that require careful adjustment.

\subsubsection{Measurement of particle morphology}

Another, newly developed instrument, the Aerosol Particle Spectrometer with Depolarization (APSD), measures light scattered at two angles from individual particles and the extent to which those particles rotate the incident plane of polarization as they pass through a focused laser beam. The light scattered by individual particles is collected by a Mangin mirror pair positioned at $90^{\circ}$ to the laser and over a $\pm 54^{\circ}$ cone, excluding an aperture in the center of the mirrors of \pm $20^{\circ}$. Two additional optical systems located off-axis at $20^{\circ}$ to either side of the laser beam and collect $\mathrm{a} \pm 13^{\circ}$ solid angle of light. A polarized filter, rotated $90^{\circ}$ to the plane of 
polarization of the incident laser, is mounted in front of one of the backscattering detectors. The side detector is used to determine the particle size using Mie theory to convert from light scattering intensity, and comparison of the signals from the two back detectors is used to determine the roughness, or deviation from sphericity. This approach is used for two reasons: 1) spherical particles will cause very little rotation of the polarization angle of scattered light from its incident direction, and 2) the intensity of depolarization depends on the asphericity of the particle and the collection angle, with angles from $140^{\circ}$ to $170^{\circ}$ showing the largest depolarization ratios from a given size and shape. The signals from the three detectors provide an asphericity index whose value is distinctly different for different types of dust. When flown on an aircraft with a CVI, as with the SP2, the APSD can measure particles in cloud-free air and in the residuals of cloud particles when sampling air from the CVI. Comparison of the signatures of cloud particle residuals to the cloud-free particles will assist in identifying not only the source of cloud nuclei but also the fraction of aerosol particles, by particle type, that is being removed by cloud processes. This addresses a fundamental question concerning the characteristics of cloud particle nuclei, particularly those that are ice crystal nuclei.

\section{Cloud measurement techniques}

Our understanding of cloud processes has advanced significantly since the early days of airborne research. With the introduction of electro-optic spectrometers (Knollenberg, $1970,1976,1981)$ the modern age of airborne cloud in situ measurements was truly launched. As will be discussed in greater detail below, the majority of the techniques most frequently used to date for measuring the properties of cloud particles originated from the work of Knollenberg. The remainder of this section describes the parameters to be measured and the techniques that are currently employed to make these measurements.

The concentration of water droplets can range from $<50 \mathrm{~cm}^{-3}$ in clouds over the remote ocean to $>3000 \mathrm{~cm}^{-3}$ in highly polluted areas or in the plumes of forest fires. Their sizes can be less than $0.1 \mu \mathrm{m}$ (haze particles) growing to larger than $6 \mathrm{~mm}$ through the processes of condensation, collision and coalescence. The concentration of ice crystals in glaciated clouds may range from several per cubic meter to tens per cubic centimeter. In mixed phased clouds the microphysical processes are more complicated and there may be hundreds of water droplets per cubic centimeter mixed with ice crystals at lower concentrations. In general, mixed phase or completely glaciated clouds will have a bewildering mixture of shapes, sizes and concentrations that challenge the measurement systems.

For complete characterization of the cloud properties and to understand their impact on the environment, we must measure the optical and geometric cross sectional (projected) area, the phase function, the shape, the density, the fall velocity and the number per volume of each hydrometeor size category. For ensembles of cloud particles we need to measure the liquid/ice water content and the extinction coefficient. The instruments that are currently deployed on modern aircraft, however, can only directly measure the size, shape, optical properties and mass of the cloud particles. The density and fall velocity have to be indirectly derived from the directly measured properties.

\subsection{Number concentrations}

All of the instruments that are currently used to measure the size and shape of individual cloud particles from aircraft use optical detection. Some, like the VIPS and Cloudscope (see below), record the image of the hydrometeors after they have impacted an exposed surface whereas the others record the image or the light scattered by the particles. Fig. 1 shows the size ranges of the 15 types of single particle spectrometers that are described in the following sections.

\subsubsection{Single particle impaction techniques}

Impactor type probes are especially useful for complementing the electro-optical probes with information about ice crystals with sizes smaller than about $100 \mu \mathrm{m}$. The particularly desirable feature of impactor probes is that they have much larger sample areas than the scattering probes and also than the optical array probes for sizes smaller than $50 \mu \mathrm{m}$. They also have potentially better resolution for discerning particle habit and the ice particle cross-sectional areas can be measured directly.

A Video Ice Particle Sampler (VIPS), developed at NCAR, is used to obtain images of particles larger than about $5 \mu \mathrm{m}$ (Heymsfield and McFarquhar, 1996; Schmitt and Heymsfield, 2009) by collecting particles in silicone oil on an $8 \mathrm{~mm}$ wide film, and then imaging them with video microscopes at two different magnifications. The VIPS captures ice crystals that impact a transparent moving belt that is exposed to the airstream and records their image with a video microscope. The usable sample volume of the VIPS is approximately $0.8 \mathrm{~s}^{-1}$ at an aircraft true airspeed of $160 \mathrm{~m} \mathrm{~s}^{-1}$. Particle collection efficiency is reduced for particles smaller than $10 \mu \mathrm{m}$, although calculations show that the collection efficiency is $94 \%$ or greater for larger particles (Ranz and Wong, 1952).

The Cloudsccope, developed at the Desert Research Institute (Arnott et al., 1994, 1995; Hallett et al., 1998) detects particles between five and a few hundred micrometers. It is an optical microscope with a CCD video camera attached. In aircraft operation a sapphire window facing the airstream is at a stagnation point of the flow so adiabatic compression heats the window to sublimate the ice crystals. From the rate of sublimation of the ice particles, their masses can be estimated. Images are digitized and analyzed to determine particle sizes, shapes and concentrations. The sample volume of the Cloudscope is about the same as the VIPS.

\subsubsection{Single particle light scattering techniques}

The airborne, in situ instruments that use optical sensing to measure size distributions of cloud droplets and ice crystals in the small particle range, i.e. $<50 \mu \mathrm{m}$, are the Model 100 Forward Scattering Spectrometer Probe (FSSP-100), Cloud Droplet Probe (CDP), Cloud and Aerosol Spectrometer (CAS), Cloud and Aerosol Spectrometer with Depolarization (CASDPOL), and Small Ice Detector (SID1 and SID2). All of them are based on the scattering of light by single particles in a focused laser beam. Table 1 lists some of the information about 


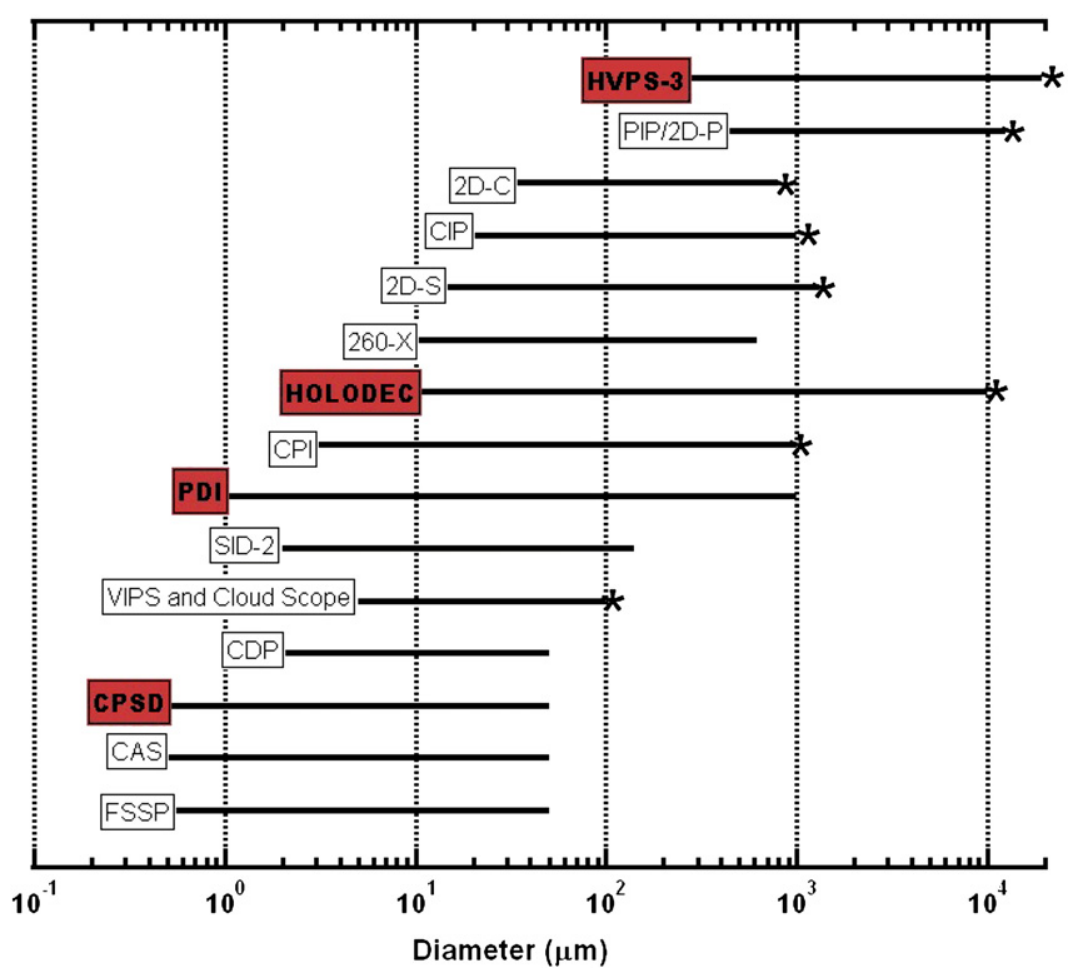

Fig. 1. This graph shows the approximate size ranges for the single particle sizing instruments that are currently used for airborne research. The * denotes an instrument whose upper size range can be extended, either by changing the resolution of the instrument (changing its minimum threshold as well) or by using some software analysis techniques to estimate sizes outside the nominal range. Instruments highlighted in red are considered emerging technology.

measurement characteristics of the different instruments currently in service.

The operating principle of the FSSP, CDP, CAS, CAS-DPOL and SID is based on the concept that the intensity of scattered light is proportional to the particle size that can be predicted theoretically if the shape and refractive index of a particle is known, as well as the wavelength of the incident light. The important thing to note is that the intensity of light scattered by a particle varies according to the angle with respect to the incident light. This theory, known by its originator, Gustaf Mie (1908) is applied in optical particle counters (OPCs) by collecting scattered light from particles that pass through a focused light beam of controlled intensity and wavelength and converting the photons to an electrical signal whose amplitude can be subsequently related back to the size of the particle.

The FSSP, CAS, CDP and SID (models 1 and 2) differ primarily in their optical configurations with respect to the angles from which the scattered light is collected. The FSSP, CDP, CPSD, CAS, CAS-DPOL and SID collect near-forward scattered light. The CAS, CAS-DPOL and CPSD also implement an additional optical system to collect near backscattered light. The near forward angles are used because the largest percentage of light scattered from a particle whose diameter is larger than the incident wavelength is in the forward direction. The backscattering signal is used for particle shape discrimination as will be described under the section on emerging technologies.

A laser provides the source of monochromatic light, lenses focus the beam through which particles pass and the light that they scatter is collected and directed to a photodetector. The resulting electrical signal is digitized and processed in a number of ways. More detailed information on the basic operating principals of the instruments can be found in Knollenberg (1981), Baumgardner (1983) and Baumgardner et al. $(2001,2002)$.

The shapes of ice crystals cannot be determined with the FSSP and CDP from a single collection angle and aspherical ice crystals will usually be undersized, depending on the deviation from spherical shape (Borrmann et al., 2000). The CAS was designed with two collection angles in order to discriminate water from ice based upon deviation from sphericity. As described in Baumgardner et al. (2005) comparison of light scattered in the forward and backward directions provides an indication, at selected sizes, of the sphericity of a particle. The CAS-DPOL has an additional back detector with a polarized filter to measure the degree of rotation of the polarized incident light caused by aspherical particles (see Section 3.4.3).

The SID was specifically designed to discriminate ice from liquid based on the pattern of light scattering (Hirst et al., 2001; Cotton et al., 2009). There are several versions of the SID, but only the SID-2 is described here. The SID-2 is able to count and size spherical cloud particles 2 to approximately $140 \mu \mathrm{m}$. The scattered light in the SID-2 is detected by a custom manufactured, hybrid photo-diode (HPD). The HPD is a segmented silicon photodiode that contains 27 independently sensed photodiode elements, with 3 central and 24 outer ones arranged azimuthally covering a forward scattering angle of $9-20^{\circ}$. The forward scattering pattern, derived 
Table 1

Specifications for cloud probes (ordered by year put in operation).

\begin{tabular}{|c|c|c|c|c|}
\hline Instrument & Vender & $\begin{array}{l}\text { Measurement } \\
\text { technique }\end{array}$ & $\begin{array}{l}\text { Measurement } \\
\text { range }(\mu \mathrm{m})\end{array}$ & $\begin{array}{l}\text { Sample volume } \\
\text { at } 100 \mathrm{~ms}^{-1} \\
\text { (liters/seconds) }\end{array}$ \\
\hline $2 \mathrm{D}-\mathrm{C}$ & PMS $^{\mathrm{a}}$ & $\begin{array}{l}\text { Optical: } \\
\text { imaging }\end{array}$ & $25-800 \mu \mathrm{m}$ & 5 \\
\hline FSSP & PMS $^{\mathrm{a}}$ & $\begin{array}{l}\text { Optical: } \\
\text { scattering }\end{array}$ & $2-50 \mu \mathrm{m}$ & 0.037 \\
\hline $260-X$ & PMS $^{\mathrm{a}}$ & $\begin{array}{l}\text { Optical: } \\
\text { imaging }\end{array}$ & $10-620 \mu \mathrm{m}$ & 2 \\
\hline CPI & $\begin{array}{l}\text { SPEC } \\
\text { Inc }\end{array}$ & $\begin{array}{l}\text { Optical: } \\
\text { imaging }\end{array}$ & $>3 \mu \mathrm{m}$ & 0.37 \\
\hline CAS & DMT & $\begin{array}{l}\text { Optical: } \\
\text { scattering }\end{array}$ & $0.5-50 \mu \mathrm{m}$ & 0.025 \\
\hline CIP & DMT & $\begin{array}{l}\text { Optical: } \\
\text { imaging }\end{array}$ & $25-1550 \mu \mathrm{m}$ & 16 \\
\hline VIPS & N.A. ${ }^{b}$ & Impaction & $>5 \mu \mathrm{m}$ & 0.5 \\
\hline Cloudscope & N.A. ${ }^{\text {b }}$ & Impaction & $>5 \mu \mathrm{m}$ & 0.5 \\
\hline SID-2 & N.A. & $\begin{array}{l}\text { Optical: } \\
\text { scattering }\end{array}$ & $2-140 \mu \mathrm{m}$ & 0.088 \\
\hline CDP & DMT & $\begin{array}{l}\text { Optical: } \\
\text { scattering }\end{array}$ & $2-50 \mu \mathrm{m}$ & 0.025 \\
\hline 2D-S & $\begin{array}{l}\text { SPEC } \\
\text { Inc. }\end{array}$ & $\begin{array}{l}\text { Optical: } \\
\text { imaging }\end{array}$ & $10-1260 \mu \mathrm{m}$ & 16 \\
\hline CIP-GS & DMT & $\begin{array}{l}\text { Optical: } \\
\text { imaging }\end{array}$ & $15-900 \mu \mathrm{m}$ & 10 \\
\hline PDI & Artium & $\begin{array}{l}\text { Optical: } \\
\text { scattering }\end{array}$ & $1-1000 \mu \mathrm{m}$ & 0.025 \\
\hline PIP & DMT & $\begin{array}{l}\text { Optical: } \\
\text { imaging }\end{array}$ & $100-6000 \mu \mathrm{m}$ & 166 \\
\hline CAS-DPOL & DMT & $\begin{array}{l}\text { Optical: } \\
\text { scattering }\end{array}$ & $0.5-50 \mu \mathrm{m}$ & 0.025 \\
\hline HVPS-3 & $\begin{array}{l}\text { SPEC } \\
\text { Inc. }\end{array}$ & $\begin{array}{l}\text { Optical: } \\
\text { imaging }\end{array}$ & $\begin{array}{l}100- \\
12,000 \mu \mathrm{m}\end{array}$ & 119 \\
\hline HOLODEC & N.A. ${ }^{b}$ & $\begin{array}{l}\text { Optical: } \\
\text { holography }\end{array}$ & $15-2000 \mu \mathrm{m}$ & Variable \\
\hline CPSD & DMT & $\begin{array}{l}\text { Optical: } \\
\text { scattering }\end{array}$ & $0.5-50 \mathrm{um}$ & 0.025 \\
\hline
\end{tabular}

${ }^{a}$ Now supported by Droplet Measurement Technologies (DMT).

b Not commercially available.

from these 27 detectors, is distinctly different for aspherical particles than for spherical water droplets, and can be used to produce a generalized classification of the ice crystal population (Cotton et al., 2009).

\subsubsection{Single particle imaging techniques}

An alternative to single particle scattering for determining the size of a particle is to capture its image. This has the advantage of extracting information about its shape as well as its size. All of the instruments currently in operation use optical arrays to capture the image; hence, their general classification as "optical array probes" or OAPs. The ones that will be described below are the two dimensional cloud and precipitation probes (2D-C and 2D-P), the cloud imaging probe (CIP), the precipitation imaging probe (PIP), the cloud particle imager (CPI), the two dimensional stereo probe (2D$\mathrm{S})$ and the high volume precipitation spectrometer (HVPS).

An important property of the imaging technique is its insensitivity to a particle's composition. This is a significant advantage over the light scattering methods, where shape, orientation and refractive index of a particle play an essential role in the determination of its size. The basic OAP is in fact a microscope with a long working distance. There are two methods used for the image recording. The first is implemented by scanning a linear photodiode array and the second provides instant particle imaging with the help of a two dimensional photodetector array. In the first case the photodiode array is scanned at the rate proportional to the particle velocity such that each time the probe moves a distance equal to one size resolution of the array, the illumination state of all the elements is recorded. The sequence of individual image slices forms a digital image of the entire particle. The scanning rate of the photodiode array depends on the air speed and pixel resolution and varies from $0.5 \mathrm{MHz}$ to $20 \mathrm{MHz}$. The advantage of the optical array method is that it allows for a continuous recording of a sequence of particles passing through the sample area; however, it is sensitive to the adjustment of the scanning rate and may result in the distortion of the aspect ratio of the image. The OAPs that use the linear array technique are the 2D-C and 2D-P (Knollenberg, 1970, 1981), the CIP, PIP and CIP-GS (Baumgardner et al., 2001), the HVPS (Lawson and Cormack, 1995) and 2D-S (Lawson et al., 2006).

Table 1 summarizes the features of each of these instruments. With the exception of the CIP-GS, all of these OAPs are monoscale in that they use a single threshold level of $50 \%$ to identify a valid image of a particle. This means that the light levels on each of the diode elements is monitored and when any one of these levels decreases below a fixed threshold (typically 50\%), the state of all of the elements in the array are recorded. The CIP-GS is a grayscale probe whose light level thresholds are programmable and as many as 256 levels can be used; however, the instrument is typically operated with three levels: $25 \%, 50 \%$ and $75 \%$. The advantage of the grayscale is that it gives additional details on the features of ice crystals and, perhaps of more importance, better defines the depth of field and allows clearer identification of particles in and out of focus. The 2D-S is different from the other OAPs only that it has two sets of orthogonal linear arrays, with 128 elements each, so that it has somewhat larger sample volume.

The second method for image recording utilizes a square photodetector array. An entire image is recorded at once when the particle is passing through the sample volume. This method requires a pulse illumination and triggering system for identification of the presence of the particle in the sample volume. The CPI is the only instrument currently in airborne operation that uses this technique, although the holographic imaging system, HOLODEC, described in emerging technologies, is similar. The CPI requires pulse illumination and therefore results in discontinuous measurements of the sequence of particles; however, the images measured by these photodetector matrices are insensitive to the airspeed as long as the duration of the pulsed illumination is short enough.

\subsection{Mass concentration}

In the previous sections we discussed methods for measuring cloud particle properties on a particle by particle basis. In addition to the properties of individual droplets and crystals, we need to measure integral properties like liquid/ice water content, phase function and optical extinction. These properties can be derived from the size distributions measured with the single particle techniques; however, unless the clouds are all water, the wide variety of crystal shapes and 
effective densities will lead to large uncertainties that can be avoided by using techniques that directly measure the integral properties.

Early measurements of cloud LWC and total condensed water content (TWC) were accomplished by collecting rime ice on rotating cylinders (Stallabrass, 1978) and, in fact, such measurements still provide the basis for important engineering standards such as the certification of aircraft for flight into icing conditions. Since then, various instrument techniques have been developed to continuously measure or infer LWC and TWC: hot-wire melting and evaporating devices, inlet-based evaporators, optical devices, and even riming devices.

\subsubsection{Heated element techniques}

In the early 1950s the first commercial instrument was developed to measure cloud LWC using a heated wire (hotwire) exposed to cloud (Neel, 1955) providing a continuous record of the structure of LWC. The device operated on the principle that the LWC could be deduced from the amount of power delivered to the wire to evaporate cloud droplets. Since then a variety of other heated-surface sensors have been developed (Merceret and Schricker, 1975; King et al., 1978; Nevzorov, 1980; Lilie et al., 2004; Vidaurre and Hallett, 2009). The basic measurement by these instruments, the amount of power delivered to a surface to keep it at a constant temperature in cloud, results from convective heat loss to the airstream and the evaporation of water droplets:

$\mathrm{P}_{\mathrm{t}}=\mathrm{P}_{\mathrm{dry}}+\mathrm{P}_{\mathrm{LWC}}$

where $P_{t}$ is the total power measured across the surface, $P_{d r y}$ is the dry-air convective heat loss from the surface, and $\mathrm{P}_{\text {LwC }}$ is the power expended to evaporate droplets. The convective heat loss $\left(\mathrm{P}_{\mathrm{dry}}\right)$ for a particular geometry can be expressed as a function of dimensionless variables and be parameterized from calibration flights in cloud-free air. The cloud LWC is then:

$\mathrm{W}_{\mathrm{L}}=\left(\mathrm{P}_{\mathrm{t}}-\mathrm{P}_{\text {dry }}\right) /\left(\left(\mathrm{L}_{\mathrm{e}}+\left(\mathrm{T}_{\mathrm{e}}-\mathrm{T}_{\mathrm{a}}\right)\right) \mathrm{VA} \varepsilon\right)$

where $L_{e}$ is the latent heat of evaporation, $T_{e}$ is the evaporative temperature of water, $T_{a}$ is the air temperature, $V$ is the air velocity, $A$ is the sensor cross-sectional area, and $\varepsilon$ is the overall collection efficiency of the sensor for droplets.

Several hot-wire devices incorporate a reference heated surface not exposed to direct impact with water droplets to improve the estimation of the dry-air convective heat losses. The overall baseline uncertainty due to the removal of the dry term is typically of the order of $0.03 \mathrm{gm}^{-3}$ (King et al., 1978) which varies according to flight maneuvers, and can be improved somewhat using the reference. With careful analysis and manual baseline zeroing, the sensitivity of some devices can be as low as several $\mathrm{mg} \mathrm{m}^{-3}$ for specific situations (Korolev et al., 1998). The different types of heated surface systems vary primarily in the type and geometries of the heated surfaces which affect their capture efficiencies for water droplets and ice particles.

The accuracy of hot-wire LWC estimates has been established by comparison to reference measurements provided by icing cylinder or blade rime ice measurements in wet wind tunnels (Stallabrass, 1978; Ide and Oldenburg,
2001). At a commonly used droplet test median volume diameter (MVD) of $20 \mu \mathrm{m}$, hot-wires have been found to agree with such reference methods to within about 15\% (King et al., 1985; Strapp et al., 2002), indicating that the hot-wire accuracy approaches the estimated accuracy of the reference method; however, the fraction of the LWC measured by cylindrical wires has been found to decrease with increasing median volume diameter (Biter et al., 1987; Strapp et al., 2002), dropping to as low as 50\% when MVD are $200 \mu \mathrm{m}$. This response roll-off with droplet MVD has been attributed to droplet splashing and re-entrainment of water after impact with the wire. Hot-wires of different geometries have been found to have varying degrees of roll-off with MVD. These differences have been exploited in a recent hot-wire device that incorporates three impact wires and a reference wire to estimate both LWC and droplet MVD (Lilie et al., 2004). Such a method for MVD estimation relies on an empirical calibration of the device in a wind tunnel and the accuracy of the tunnel MVD estimate itself. The sensitivity to the droplet distribution has not been determined.

Wire geometries with specially designed capture volumes are also used to estimate TWC in mixed-phase conditions. With an independent measurement of LWC, the ice water content (IWC) can also be estimated. King and Turvery (1986) proposed a wire-wound, cup-like, TWC device rather than a cylindrical wire, operating as an ice-particle melting device where IWC could be calculated in a similar manner to a LWC device. In the mid 1990s, the Russian Nevzorov LWC/TWC device was introduced into western airborne measurements (Nevzorov, 1980; Korolev et al., 1998). Several newer hot element IWC devices have since been developed based on similar principles (Lilie et al., 2004; Vidaurre and Hallett, 2009). In the Nevzorov hot-wires a cylindrical 'LWC' hot-wire and a non-cylindrical wound-wire 'TWC' collector with a conical capture volume pointed into the airflow are each attached to the leading edge of a flow-correcting vane.

Conceptually, ice particles are assumed to impact and bounce off the surface of the cylindrical LWC wire, resulting in very little heat loss, while liquid droplets spread out into a film, and quickly evaporate resulting in a relatively large heat loss. The TWC collector is assumed to capture both ice particles and water droplets efficiently and the heat loss to the wire is a result of both the liquid and ice particle mass of the cloud.

While non-cylindrical TWC sensors have been found to measure most of the typical cloud LWC (Ide, 1999; Strapp et al., 2002; Lilie et al., 2004), significant fractions of ice particles have been shown in high-speed videos to be ejected from the capture volume (Emery et al., 2004; Strapp et al., 2005; Korolev et al., 2008). Determining the absolute IWC efficiencies of hot-wire sensors has been impeded by the lack of a suitable reference standard for ice particle testing. Although facilities now exist with a reference IWC estimate (e.g. Strapp et al., 2008), ice particles in these facilities are produced by shaving ice blocks or similar methods, and complementary aircraft-based testing is required in natural ice crystals (Isaac et al., 2006; Korolev et al., 2008).

\subsubsection{Inlet-based evaporating systems}

For all instruments in this class hydrometeors enter an inlet exposed directly to the air stream. The inlet acts as a deep capture volume so that the bouncing and re- 
entrainment observed in hot-wire devices (Emery et al., 2004; Strapp et al.,2005; Korolev et al., 2008) is minimized, providing a measurement advantage for large water drops (Twohy et al., 2003) and large ice particles. TWC is deduced from enhanced humidity due to hydrometeor evaporation, measured usually by an absorption hygrometer such as a Lyman-alpha or tunable diode laser. Ruskin (1965) describes an isokinetic flow-through device with a $1 \mathrm{~cm}$ inlet, in which captured hydrometeors would melt and evaporate due to warming by heating elements and impact with fine screens. Similar devices are described by Kyle (1975) and Nicholls et al. (1990), where the former was used for measurements of heavy rain in convective clouds, and the latter primarily for measurements in ice clouds.

More recently the Fast In Situ Stratospheric Hygrometer (FISH) was developed based on the Lyman- $\alpha$ photo-fragment fluorescence technique (Zöger et al., 1999; Schiller et al., 2008). The FISH is sensitive to $\mathrm{H}_{2} \mathrm{O}$ mixing ratios from approximately 0.5 to $1000 \mathrm{ppmv}$ and thus well suited for investigations in the upper troposphere and lower stratosphere over a large dynamic range. The time resolution is $1 \mathrm{~s}$, determined by the exchange time of air through the measurement cell. The air enters by a forward facing inlet tube mounted outside of the research aircraft sampling total water, i.e., the sum of both gas-phase molecules and ice particles. The large ice particles are sampled with enhanced efficiency compared to the gas molecules (Schiller et al., 2008). The aspiration coefficient (or enhancement factor) of the inlet increases from approximately unity for particles with radii smaller than $0.3 \mu \mathrm{m}$ to its maximum value $\mathrm{E}_{\max }$ which is typically achieved for particle radii larger than 3$4 \mu \mathrm{m}$. The value of $E_{\max }$ depends on the air density, temperature and velocity and can vary between 3 and 10 .

Weinstock et al. (2006) describe the Harvard Total Water (HTW) isokinetic evaporator specifically designed and calibrated for low-IWC cirrus measurements as small as several milligrams per cubic meter. Another instrument is the Closed Path TDL Hygrometer (CLH), a sub-isokinetic sampler that concentrates hydrometeor mass relative to free-stream water vapor mass, thereby enhancing its ability to measure condensed water contents $<10 \mathrm{mg} \mathrm{m}^{-3}$ (Davis et al., 2007). As with the FISH, particles are not sampled isokinetically so that adjustments must be made to account for particle collection efficiency as a function of size.

The Counterflow Virtual Impactor (CVI), developed to measure evaporated hydrometeor residuals, has also been used to measure TWC (Noone et al., 1988, 1993; Twohy et al., 1997). Hydrometeors of sufficient size enter the inlet against a counterflow of pressurized, initially dry, carrier gas air and travel into an evaporation chamber. The humidity subsequently measured is solely due to hydrometeor evaporation and independent of the free-stream humidity. The CVI has a detection limit as low as $1 \mathrm{mg} \mathrm{m}^{-3}$, but suffers from hysteresis at relatively high water contents. Due to the counterflow, CVI instruments typically have a 'cut-size' of the order of 4-8 $\mu \mathrm{m}$ below which particles are not detected.

There still remains the need for an instrument that can measure total water contents higher than $5 \mathrm{gm}^{-3}$, levels of water that can be found in deep convection. All of the instruments described above saturate when LWC or IWC is larger than this value.

\subsubsection{Other sensing techniques for LWC}

Another instrument that uses phase change to determine hydrometeor mass is the Rosemount icing rate sensor that is sensitive only to supercooled water droplets. The measurement technique is based on changes in the natural frequency of an oscillating cylinder due to accretion of ice on its surface. The cylinder is vibrated using magnetostrictional excitation that causes axial oscillations of the cylinder at a natural frequency of $40 \mathrm{kHz}$. As supercooled water droplets impact the cylinder they freeze and their added mass decreases the resonance frequency, a change that is proportional to the mass and, through calibration, is converted to LWC. More details may be found in Baumgardner and Rodi (1989), Heymsfield and Miloshevich (1989), Cober et al. (2001a,b), and Mazin et al. (2001).

The Particulate Volume Monitor (PVM-100A) is closely related to the class of instruments termed "laser-diffraction particle-sizing instruments" (Azzopardi, 1979; Hirleman et al., 1984). In the PVM (Gerber, 1991) a collimated laser irradiates ensembles of particles which scatter light onto a narrow circular region of a sensor. Each sector of the sensor corresponds to different scattering angles. The PVM has a large-area photo diode in front of which is placed a fixed spatial filter with varying transmissions in the radial direction that transform the scattered light into an integrated particle volume concentration, $C_{v}$ (volume of the particles per volume of the suspending medium). The PVM has been used primarily to measure $C_{v}$ in warm water clouds where $C_{v}=\mathrm{LWC}^{-1}$ ( $\rho=$ water density). The PVM has a second channel that converts the scattered light into the integrated particle surface area (PSA) of drops using a different set of spatial filters. The ratio of LWC/PSA is proportional to the effective radius of the droplet size distribution (see Section 3.3).

The PVM Model 100A, because of its fast response time, at $1000 \mathrm{hz}$ sampling rates can resolve LWC with structure at $10 \mathrm{~cm}$ scales at an aircraft speed of $100 \mathrm{~m} \mathrm{~s}^{-1}$. The LWC channel of the PVM-100A has an accuracy of $~ 10 \%$ over a droplet size range of about $4 \mu \mathrm{m}$ to $30 \mu \mathrm{m}$ diameter, while the PSA channel measures with similar accuracy to about $70 \mu \mathrm{m}$. The principal weakness of the aircraft PVM-100A is the limited response as a function of droplet size (Wendisch, 1998; Wendisch et al., 2002). Whereas the design calls for an upper droplet size response of $\sim 45 \mu \mathrm{m}$ diameter for LWC measurements, measurements have shown that its response rolls off at about $30 \mu \mathrm{m}$ diameter.

The strengths of the PVM-100A are its fast response time, accuracy and precision over the indicated droplet size range, and stability of the measurements. The probe's fast response has permitted new looks at fine-scale behavior in clouds including the finding of a "scale-break" in the LWC power spectra of clouds (Davis et al., 1999; Gerber et al., 2000), and at the entrainment effect in stratocumulus (Gerber et al., 2005) and cumulus (Gerber et al., 2008).

\subsection{Optical properties}

\subsubsection{The cloud extinction probe}

The Cloud Extinction Probe (CEP) was designed by the Cloud Physics and Severe Weather Research Section of Environment Canada for measuring the extinction coefficient in clouds and precipitation (Korolev et al., 2001). The CEP 
utilizes a transmission method based on the measurement of the attenuation of light between the receiver and transmitter. The advantages of the transmission technique are: (1) calculations of the extinction coefficient from first principles based on the Beer-Bouguer law, (2) a large sample volume, which enables statistically significant measurements in clouds with low concentrations, (3) minimal effect of ice shattering on measurements due to large spatial separation (up to $10 \mathrm{~m}$ or higher) of transmitter and receiver.

The CEP consists of an optical unit that combines a transmitter and receiver as well as a retro-reflector. A collimated light beam is generated by an optical system consisting of a high intensity LED with the wavelength $\lambda=635 \mathrm{~nm}$, diffuser, condenser, pinhole and objective. The beam travels from the optical unit to a retro-reflector then returns the same distance back to the optical unit. After passing though the objective and beam-splitter its intensity is monitored by a photodetector. The CEP was installed on the National Research Council's Convair-580 with the optical unit inside the wing tip canister and the retro-reflector inside a hemispherical cap at the rear side of a PMS probe canister. The distance between the optical unit and the retro-reflector was $L=2.35 \mathrm{~m}$. Depending on aircraft the separation between the optical unit and the retro-reflector may vary from 1 to $10 \mathrm{~m}$. The CEP was designed to operate in all weather conditions. Based on the flight tests the threshold sensitivity of the probe was found to be approximately $0.2 \mathrm{~km}^{-1}$ and the upper limit of the measured extinction coefficient is estimated to be no less than $200 \mathrm{~km}^{-1}$.

\subsubsection{The polar nephelometer}

The 'Polar Nephelometer' constructed at the Laboratoire de Météorologie Physique (LaMP, Clermond-Ferrand, France) is the only instrument that can make direct, in situ measurements of the scattering phase function of cloud particles over a broad range of sizes from a few micrometers to about $1 \mathrm{~mm}$ diameter (Gayet et al., 1997, 1998; Crépel et al., 1997).

The probe measures the scattering phase function between $3.5^{\circ}$ and $169^{\circ}$ of an ensemble of cloud particles intersecting a collimated laser beam near the focal point of a paraboloidal mirror. The laser beam is provided by a highpower $(1.0 \mathrm{~W})$ multimode laser diode operating at $\lambda=804 \mathrm{~nm}$. The light scattered at polar angles from 10 to $165^{\circ}$ is reflected onto a circular array of 41 photodiodes. At small angles $\left(3.5^{\circ}<\theta<10^{\circ}, 165^{\circ}<\theta<169^{\circ}\right)$, where the angular resolution is $1.58^{\circ}$, optical fibers are used to collect and transmit the light to photodiodes. The resolution is $7^{\circ}$ for larger angles $\left(10^{\circ}<\theta<165^{\circ}\right)$. The sensitive volume $\left(0.2 \mathrm{~cm}^{3}\right)$ is defined by a $10-\mathrm{mm}$-long and 5 -mm-diameter laser beam. The data acquisition system provides a continuous sampling volume by integrating the measured signals of each of the detectors over a selected period.

From the measurements of the scattering phase function, particle types, i.e. water droplets and ice crystals with different habits, can be distinguished and the scattering coefficient and asymmetry parameter derived. The Polar Nephelometer measurements are generally validated by comparing the microphysical parameters retrieved from the scattering phase function (Dubovik, 2004) with those derived from direct size distribution measurements by light scatter- ing and imaging probes. The inversion method enables the retrieval of volume particle size distributions and additional microphysical and optical parameters such as liquid water content, particle concentration, scattering coefficient and the asymmetry parameter. Mie theory is used to describe light scattering characteristics for water droplets and small, quasispherical ice particles. For large ice crystals, the geometrical optics approximation is used.

\subsubsection{Cloud integrating nephelometer}

The Cloud Integrating Nephelometer (CIN), first termed the "g-meter", was developed by Gerber Scientific Inc. to address the need for direct, in-situ measurements of the asymmetry parameter, $g$, and the optical extinction coefficient, $B_{e}$, at visible wavelengths in clouds (Gerber, 1998; Gerber et al., 2000). While accurate measurements of $g$ in water clouds could be obtained through application of Mie theory to measured distributions of spherical droplets, the same was not possible for clouds composed of ensembles of ice crystals, with the exception of the Polar Nephelometer that measures the phase function from which $g$ can be derived.

The CIN operates in much the same way as integrating nephelometers that are used for aerosol measurements. A collimated laser-diode beam irradiates cloud particles that pass through the CIN aperture during aircraft flight. These particles scatter light out of the direct path of the laser beam to a set of four Lambertian sensors. The absolute and relative magnitudes of the signals received by each of the sensors are used to infer the light scattering properties of the cloud particles. The CIN is designed to measure the asymmetry parameter and extinction coefficient of cloud particle ensembles whose diameters range from about 4 to $2500 \mu \mathrm{m}$ diameter at the wavelength of the instrument laser $(635 \mathrm{~nm})$. The CIN measures the intensity of light reaching each sensor (photomultiplier tubes) as a voltage that is then multiplied by a set of scaling constants. The first set of scaling constants determines the relative response of each of the four sensors and the second converts the voltages to light extinction values. Provided that the missing fraction, $f$, of light scattered into the forward $10^{\circ}$ is known, then the asymmetry parameter can be directly calculated from extinction values (Gerber et al., 2000):

Values of $f$ are large but tightly constrained because forward diffraction is very close to one half of the total scattered energy in the geometric optics limit. For droplets, independent of droplet size, $f=0.53 \pm 0.01$ (Garrett et al., 2001). For ice crystals, $f=0.57 \pm 0.02$ for a wide range of plausible sizes and shapes (Garrett, 2008). The related uncertainty in calculations of $g$ is \pm 0.01 and $5 \%$ in $B_{e}$. Calculation of voltage to extinction relationships in the CIN is achieved through comparison with either the PSA channel of a PVM-100 probe (Gerber et al., 2000), or more directly through comparison with groundbased transmission measurements in fog (Gerber et al., 2004). Additional tests may be done in post-analysis through intercomparisons with other aircraft probes based on measurements within liquid clouds where general instrument performance tends to be well characterized (Garrett et al., 2001; Garrett, 2007).

The CIN sampling cross-section is about $30 \mathrm{~cm}^{2}$, so the sampling volume is 3001 per second at an aircraft speed of $100 \mathrm{~m} / \mathrm{s}$. 


\subsection{Emerging technology}

There are a number of relatively new technologies that have been developed in recent years but have not yet undergone the same rigorous scrutiny as those described above. The preliminary results from the initial applications of these new measurement techniques are encouraging and deserve further evaluation. Some of these technologies are available commercially, such as the PDI and CAS-DPOL, while others like the HOLODEC have been developed at universities and research institutes.

\subsubsection{Phase Doppler interferometry}

Instruments known as the Phase Doppler Interferometer (PDI) are based on light scattering interferometry (Bachalo, 1980,1994; Bachalo and Houser, 1984; Albrecht et al., 2003), an extension of the well known Laser Doppler Velocimeter technique (Durst et al., 1981). The scattering by spheres much larger than the instrument wavelength is approximated by geometrical optics. The method is independent of the laser beam and light scattering intensities except for the need to produce adequate signal-to-noise ratio.

PDI instruments use a laser operating in single longitudinal mode to produce a coherent, polarized beam that is split into two equal intensity beams, typically with an acoustooptic modulator known as a Bragg cell which also shifts the frequency of one of the beams. Two equal-intensity parallel beams are focused to an intersection region to form the sample volume region. An interference fringe pattern is formed with the fringe spacing determined by the laser wavelength and beam intersection angle. Spherical particles passing through the beam intersection scatter light which is detected by the receiver. The receiver, located at a suitable off axis angle, is comprised of a lens to collect the light and image it to a small selectable aperture. The collected light is partitioned into three segments and directed to three photodetectors. The signals have a sinusoidal character that are detected and processed using digital sampling and Fourier transform. Each detector forms a nearly identical signal that is phase shifted relative to those from the other detectors. The frequency of each signal is proportional to the particle velocity. Using geometrical optics theory, the phase shift between each of the three possible signal pairs from the three detectors is linearly proportional to the droplet diameter. With three pairs of detectors, optical phase ambiguity (phase shifts greater than $360^{\circ}$ ) is resolved and redundant measurements of each droplet are obtained for additional signal validation and averaging.

The PDI, measures drop velocity and size. The velocity measurement is useful diagnostic that, when compared to the aircraft velocity, confirms the accuracy of the drop sizing. The PDI technique is capable of measuring drop diameters in the size range of approximately $1-1000 \mu \mathrm{m}$. A single instrument is limited to a size dynamic range of approximately 50:1 due to photodetector performance. Minimum drop size is determined by the smallest necessary signal-to-noise ratio, and for instruments designed for cloud drop measurements, it is estimated to be between 1 and $3 \mu \mathrm{m}$. The maximum size is limited by the assumption of drop sphericity. For realistic operations, the upper cloud drop size range is limited primarily by counting statistics and not instrument capabil- ities. In stratocumulus, a reasonable upper-bound has been found to be $\sim 100 \mu \mathrm{m}$ diameter (Chuang et al., 2008). The sizing principal is insensitive to changes in droplet velocity and current signal data processing technology permits measurements to speeds in excess of $200 \mathrm{~ms}^{-1}$.

Since its inception in 1982, the method has been applied widely to a large range of ground-based spray characterization applications; however, it has not been used on aircraft except for a limited number of applications and there are few publications where measurements from the PDI have been benchmarked against the more traditional "legacy" instruments like the FSSP (Chuang et al., 2008; Small and Chuang, 2008).

\subsubsection{Holography}

Holography provides the three-dimensional position, shape, and size of each particle in a dilute collection of cloud droplets/ice particles inside a localized, three-dimensional sample volume. In-line holography is particularly useful for atmospheric applications because of its relatively simple and robust setup. In-line holography has been applied to various problems of atmospheric interest since 1975 using photographic film/plates (Trolinger, 1975; Kozikowska et al., 1984; Uhlig et al., 1998; Borrmann and Jaenicke, 1993; Brown, 1989) or digital cameras (Lawson and Cormack, 1995; Raupach et al., 2006; Fugal et al., 2004; Fugal and Shaw, 2009).

Holography has several advantages relative to other cloud microphysical measurement techniques: it can provide a well defined sample volume, independent of particle size (given an appropriate reconstruction method (Fugal et al., 2009) and air speed, it is able to measure over a wide range of particle sizes, it provides relative spatial locations of particles in its sample volume, thereby allowing for studies of particle clustering or ice crystal shattering (Fugal and Shaw, 2009) and it allows relatively large, contiguous volumes of cloud to be sampled instantaneously, without requiring assumptions regarding statistical homogeneity, etc. The primary, relative disadvantages of digital holography are the large data file sizes and the added complexity involved in data processing, which includes digital reconstruction and particle detection and characterization.

An in-line hologram is an interference pattern, a "virtual image", resulting from the superposition of an incident plane wave and light scattered by the dilute suspension of illuminated particles. The virtual image reconstructs as a blurry background appearing around the reconstructed "focused" real image. The effect of the virtual image on the quality of the real image can be reduced (Raupach, 2009) and this method can also be used to probe the internal structure of ice particles in holograms. The "focus" position for the reconstructed real image of a given particle yields the three-dimensional position of the particle, and the image at this position gives the shape and size of that particle.

Under typical aircraft flight conditions the sampling rate of an in-line hologram instrument is not dependent on air speed, but on the individual sample volume size and the frame rate of the camera. The minimum particle detection size is, in general, determined by the greater of two criteria: Either greater than two pixels wide to resolve a particle or the diffraction limited resolution (Fugal et al., 2009). The 
maximum detection size is some fraction of the detector size and typically determined by the automated hologram processing code's ability to reliably bring such a large particle in focus (Fugal et al., 2009). Particle sizes can be calculated by counting the number of pixels contained in each focused particle and calculating an equivalent diameter for a circle of equal area. For spherical particles this pixel counting method gives a precision approximately equal to the square root of the pixel size (Lu et al., 2008). Fugal et al. (2004) and Pu et al. (2005) discuss the accuracy of sizing particles using digital inline holography.

\subsubsection{Distinguishing Ice crystals from water droplets}

The CAS-DPOL, a modification to the CAS (Baumgardner et al., 2001), is able to differentiate water droplets from ice crystals in mixed phase clouds. The optical system is identical to the CAS with the addition of another back detector, collecting over the same angle but with a polarized filter $90^{\circ}$ to the polarization of the incident light. Hence it will only measure scattered light out of the incident polarization plane. Spherical water droplets will not rotate the polarization but frozen water droplets and aspherical ice crystals will. As with the APSD (described in Section 2.4.2), the signals from the three detectors can uniquely identify a spherical from a nonspherical cloud particle and even very small asphericities, such as a newly frozen water droplet, will produce significant depolarization signals.

Tthe CAS-DPOL has been evaluated in the Aerosol Interaction and Dynamics in the Atmosphere (AIDA, http:// www.imk-aaf.kit.edu/73.php) cloud chamber under conditions when water droplets were freezing and changing from spheres to other shapes. The transition from water to ice was clearly detected and the larger droplets were observed first to freeze and while the smaller droplets froze at a slower rate. This has been observed previously in laboratory studies of droplet freezing (Gonda and Takahashi, 1984).

\section{Radiation measurement techniques}

Solar radiation is the Earth's most significant energy source, the principal driver of circulation dynamics, chemistry and interactions among the atmosphere, oceans, ice, and land that maintain the terrestrial environment and biosphere. Solar radiation is scattered and absorbed within the atmosphere and at the Earth's surface; hence, measurements of solar and infrared radiation over a wide range of frequencies are essential for understanding changes in climate related to processes that impact the radiative balance of the earth. In recent years there have been advances in spectral radiometry, actinic flux density measurements and stabilization of aircraft radiometers that will be highlighted in the following sections.

\subsection{Solar spectral radiometry}

Airborne spectral radiometers have been utilized more frequently over the past decade after a historical reliance on broadband radiometers for examining problems such as cloud absorption, aerosol forcing, and the fundamental measurement of surface and atmospheric albedo. Perhaps the best example of the success of spectrally resolved irradiance was in the resolution of anomalous cloud absorption. The initial report by Cess et al. (1995) on a bias between modeled and measured broadband cloud absorption was one of the motivating factors for the development of the Solar Spectral Flux Radiometer (Pilewskie et al., 2003) and, independently, the actively stabilized Albedometer (Wendisch et al., 2001). Although discrepancies still remain between spectral measurements and models, the new spectral measurements determined unequivocally that spectral absorption features in clouds could be explained by water and that no "unexplained absorber" was required to reconcile observations and theory within experimental and computational uncertainties (Pilewskie et al., 2005).

The basic elements of the spectral radiometer are a foreoptic, light collector or optical inlet, that collects the light via a diffusive element which transmits optical power proportional to the cosine of the angle that the incident light makes with respect to the aperture normal. Light from the diffuser may be transmitted directly onto the entrance slit of a spectrometer where it is dispersed into its component wavelengths; however, for ease of aircraft integration and field calibration, some of the instruments implement optical fibers to transmit light from the aircraft skin-mounted light collector to the rack mounted spectrometers located within the aircraft cabin. The light collectors, or optical inlets, are small lightweight devices which greatly simplify aircraft integration, improve the adaptability to a broad collection of platforms and make field calibration easier and more accessible. An additional benefit of fiber optics is that they highly depolarize incident light thus reducing the impact of polarizing optical elements on radiometric accuracy.

\subsection{Actinic flux density measurement}

Airborne measurements of spectral, actinic flux density determine frequencies of atmospheric photolysis processes. There are two radiometric approaches to derive frequencies of photodissociation processes: filter radiometry and spectroradiometry (Hofzumahaus, 2006). Filter radiometry is a technique where the spectrally integrated solar actinic flux density is measured in a confined spectral interval. The receiver optics consists of a series of frosted quartz domes that act as diffusers with nearly isotropic response within one hemisphere (Volz-Thomas et al., 1996). The photons are directed to a detector after filtering for frequencies that emulate the spectral sensitivity of the molecule-specific products of absorption cross sections and quantum yields. A filter radiometer therefore covers only one photolysis process and needs calibration with a reference instrument. Due to their fast time response (about $1 \mathrm{~s}$ ) and compact design, filter radiometers are technically well suited for airborne operations.

Spectroradiometry is based on measurements of spectral actinic flux density in the UV-VIS spectral range. This is the most versatile method to determine photolysis frequencies because $J$ can be derived for any molecule if the photolysis process is covered by the instrumental wavelength range and the molecular parameters are known. As in the case of filter radiometers, optical receivers typically consist of frosted quartz domes to obtain an isotropic angular response within a hemisphere. The collected photons are transmitted to a monochromator where the radiation is detected as a function 
of wavelength. Scanning systems mostly use photomultiplier tubes as detectors while multichannel spectrometers utilize a photodiode array or a Charge Coupled Device. Scanning spectrometers typically run through a spectrum within 10$90 \mathrm{~s}$ (Shetter and Müller, 1999; Hofzumahaus et al., 2002; Shetter et al., 2003). The time-consuming scanning procedure can lead to a distortion of the spectrum under conditions of inhomogeneous clouds or surface albedo. Furthermore, motorized parts within the instrument can influence stability on moving platforms. Except for minor corrections, all spectroradiometers can be calibrated absolutely with spectral irradiance standards that are be traced to national standards.

\subsection{Stabilized radiometer platforms}

Aircraft measurements of solar broadband or spectral irradiance are typically done by simply mounting an identical set of broadband or spectral solar radiometers directly to the top and bottom of a research aircraft to simultaneously measure the down and up-welling solar irradiance at a given altitude; however, radiometers rigidly attached to an aircraft will tilt along with the aircraft during flight. These variations from a horizontally level position will introduce offsets and fluctuations into the measured signal that are not due to any change in the magnitude or angular distribution of the solar radiation in the sky. This effect is most pronounced in solar irradiance measurements because sunlight is typically dominated by a non-isotropic direct component, i.e. the light coming directly from the sun, with a secondary contribution from the diffuse sunlight scattered from the sky. The direct component of the solar radiation scales with the cosine of the solar zenith angle; however, on an aircraft, the cosine of the solar zenith angle with respect to the radiometer is not only a function of the position of the sun but also of the pitch, roll, and heading of the aircraft. Such changes in solar zenith angle with respect to the radiometer will change the measured irradiance, even though the sun's position in the sky, and the direct component of the intensity, has not changed. It is typical to see significant changes in the measured solar irradiance generated by nothing more than heading changes in the aircraft.

In recent years, a number of stabilized platforms have been developed for aircraft that correct for this problem in solar irradiance measurements by keeping the radiometers horizontally level in flight (Wendisch et al., 2001; Bucholtz et al., 2008). They operate by measuring both the changes in the attitude of the platform with respect to Earth centered coordinates and with respect to the aircraft. Corrections are then made for those changes through a series of actuators and motors. The attitude of the platform is obtained from a real time Inertial Navigation System (INS) which consists of a highly accurate Inertial Measurement Unit (IMU) for rate and acceleration data, a Global Positioning System (GPS) for positional information, and software for real-time analysis. The IMU uses fiber optic gyros (FOGs) to measure the angular rate of pitch, yaw and roll and silicon accelerometers to measure linear acceleration. Since IMUs inherently tend to drift over time, the GPS is used to compensate for this effect.

The first active, horizontally stabilized system specifically developed for aircraft radiometer measurements is described by Wendisch et al. (2001) and Jäkel et al. (2005). This system keeps an airborne spectral albedometer and actinic flux radiometer level to better than $\pm 0.2^{\circ}$ for pitch and roll angles within the range of $\pm 6^{\circ}$. A next generation version of this platform, named the Stabilized Platform for Airborne Solar Radiation Measurements (SPARM) is currently under development for the National Center for Atmospheric Research (NCAR) HIAPER research aircraft.

Bucholtz et al. (2008) describe the Stabilized Radiometer Platform (STRAP), another actively stabilized, horizontally level platform for aircraft radiometer measurements. STRAP can hold up to three radiometers level to better than $\pm 0.02^{\circ}$ for aircraft pitch and roll angles of up to approximately $\pm 10^{\circ}$. It corrects for angular offsets at a rate of $100 \mathrm{~Hz}$ and can compensate for most pitch and roll changes experienced in normal flight and in turbulence. The STRAP design differs from the stabilized system described by Wendisch et al. (2001) primarily through the attachment of the STEAP IMU directly to the bottom of the payload plate that holds the radiometers. In the Wendisch et al. (2001) design, the IMU is fixed to the aircraft.

Stabilized platforms minimize errors introduced into the solar irradiance measurements due to a tilted instrument and greatly simplify post processing of the data because techniques to correct the measured irradiance back to a level platform are no longer needed. In addition, because stabilized platforms keep the solar radiometers level for pitch and roll angles of anywhere from $\sim 6^{\circ}$ to $\sim 10^{\circ}$, the quality of useful data from any given flight is significantly increased and the restrictions on flight patterns are greatly reduced.

\subsection{Future outlook for radiometery}

Airborne microwave remote sensing for satellite validation studies (e.g. (Blackwell et al., 2001; Crewell et al., 1994; Lobl et al., 2007) has played an important role in the past and will certainly continue to do so. In addition, airborne simulators can provide an opportunity to test new instrument techniques before they are brought to space. An example of this is the application of submillimeter observations to derive global ice water path distributions (Buehler et al., 2007) for which the manufacturing of a simulator is currently underway. A particular advantage of airborne observations is their ability to bridge the scale between point wise, in-situ and large-scale satellite observations. Because of the relatively low spatial resolution of microwave satellites, beam filling problems are particularly evident for highly variable parameters like clouds and precipitation. Airborne observations can help to address scale related issues in both satellite retrieval algorithms and in larger scale atmospheric modeling. In this respect sensor synergy with auxiliary instrumentation like cloud radar, lidar and/or solar and infrared radiation observations is highly valuable as atmospheric parameters can be derived with much improved accuracy. A classical example is the determination of liquid water profiles over ocean. Here the drop size dependent radar signal can be adjusted by the integral amount that is provided by microwave radiometers with high accuracy. Sensor synergy allows the most complete view on the atmospheric state and therefore provides valuable input for process studies. The recent development of research aircraft with relatively large payloads and long 
distance coverage, e.g. HIAPER in the U.S. and HALO in Germany, will certainly push this development.

\section{Measurement challenges}

All of the measurement techniques previously described are susceptible to uncertainties and limitations that are inherent to the technology that has been implemented in the sensors. Within the references that are related to each of the instruments the reader will find detailed analyses of the uncertainties and limitations associated with the measurement technique and we urge those who wish to use these instruments or to analyze the data taken with them to read these articles carefully. Failure to understand the limitations or potential errors associated with the instrument of interest jeopardizes the quality of the analysis and the fidelity of conclusions that may be drawn from such evaluations.

There are many challenges that face the science community with respect to the measurement of aerosols and clouds from airborne platforms. Some of the more daunting ones are those summarized in the following sections.

\subsection{Anisokinetic sampling}

By definition isokinetic sampling is when the air at the sample point, and the embedded particles, are at free stream velocity. The particle velocity with respect to the aircraft is determined by their fall speed, the local wind vector and the aircraft velocity. Anisokinetic sampling is when the air is accelerated or decelerated with respect to the free stream. In either case the effect is to change the thermodynamics of the air and alter particle trajectories leading to potential errors in the measured particle properties.

Anisokinetic sampling is caused by the presence of a solid body of sufficient size to alter the air mass velocity. In aircraft applications the aircraft body or the instrument sampling inlets will potentially contribute to this problem. For the case of air flowing past a fuselage, in some regions streamlines will converge, leading to compression and acceleration, particle trajectory convergence and enhanced concentrations. In other regions where the flow separates and diverges, there can be no particles, i.e. shadow zones.

Shadow and enhancement zones are the most prominent aerosol measurement bias caused by an aircraft body; however, there are other issues to be considered. Due to the aircraft body, the sampling air is decelerated, which, according to the laws of thermodynamics leads to an increase in air temperature (ram heating). Depending on the aircraft airspeed and the magnitude of deceleration, this increase can be as much as $30 \mathrm{~K}$. Particles passing these zones of increased temperature may partially evaporate and thus change size as well as chemical composition. In zones of airflow acceleration, the temperature is decreased, which can lead to condensation of vapor molecules and even formation of ice crystals in supercooled clouds (Heymsfield, 2010). Measurements well outside the aircraft boundary layer are important, not only to exclude particle losses in this turbulent flow region, but also to prevent memory effects caused by resuspension of particles previously deposited on the fuselage. On the NASA DC-8 research aircraft, Vay et al. (2003) showed that air from a cabin air vent stayed within the aircraft boundary layer for at least $20 \mathrm{~m}$ downstream. The investiga- tions by Vay et al. (2003) also underscore the importance of knowing the streamlines along the aircraft in order to prevent artifacts caused by air vents upstream of sampling ports.

An airborne aerosol sampling system consists of an inlet, located outside the aircraft, and the sampling line that transports the particles from the inlet to the measurement device inside. The overall sampling efficiency of an inlet is the product of the inlet efficiency and the transport efficiency through the sampling line. The inlet efficiency is derived as the product of the fraction of particles entering the inlet (aspiration efficiency) and the fraction of these particles being transmitted through the inlet (transmission efficiency). Individual efficiency values range from 0.0 to 1.0 (or sometimes larger). For many processes, the above efficiencies can be determined from the available empirical equations (Hinds, 1999; Baron and Willeke, 2005; Vincent, 2007). However, empirical equations for efficiencies are not easily established for some inlet configurations, and for such cases the efficiencies must be determined differently (e.g., by wind tunnel studies).

The major goal of airborne aerosol measurements is to carry out representative sampling; i.e. the investigator wants to know the physical and chemical state of the aerosol particles in the undisturbed atmosphere. Hence it is important to quantify these processes. In principle, there are four ways to accomplish this task: the use of empirical equations from the literature (e.g., given in Baron and Willeke, 2005 or Von der Weiden et al., 2009), Computation Fluid Dynamic (CFD) modeling studies (e.g., Ram et al., 1995; Cain et al., 1998; Twohy, 1998; Dhaniyala et al., 2003; Krämer and Afchine, 2004; Eddy et al., 2006), experimental quantification of particle losses by wind tunnel studies (e.g., Chandra and McFarland, 1997; Cain et al., 1998; Murphy and Schein, 1998; Twohy, 1998; Hegg et al., 2005; Hermann et al., 2001; Irshad et al., 2004) or in-flight testing and comparison (Huebert et al., 1990; Porter et al., 1992; Weber et al., 1999; Blomquist et al., 2001; Huebert et al., 2004; Moore et al., 2004; Hegg et al., 2005).

\subsection{Cloud particle breakup}

Sampling artifacts by definition are any distortion in the sampled size-differentiated concentrations relative to that in the atmosphere. In airborne research the high airspeed of the measurement platform is primarily responsible for potential artifacts. The most prominent of these might occur when the aircraft flies into clouds where protruding structures of an instrument have surfaces where cloud droplets or ice crystals might impact and break-up (e.g., Cohen, 1991; Yarin, 2006; Vidaurre and Hallett, 2007). Weber et al. (1998) compared measurements made downstream of two inlet systems on the NCAR C-130: one with a relatively large inlet surface area compared to the inlet sampling cross-sectional area (large area ratio) and one with a relatively small inlet surface area compared to the inlet sampling cross-sectional area (small area ratio). The authors found that water droplets impacting the lips (leading edge) of the large area ratio inlet led to the generation of many small particles downstream. Sampled particle concentrations were increased by at least an order of magnitude compared to the measurements downstream of the small area ratio inlet.

The shattering of ice particles into small fragments, prior to entering the probe's sample volume, can cause detection of 
multiple artificial c small ice particles and result in an overestimation of the concentration (Emery et al., 2004; Isaac et al., 2006). The effect of shattering on ice particle measurements has recognized since 1985 (e.g. Gardiner and Hallett, 1985; Gayet et al., 1996; Field et al., 2003, 2006; Korolev and Isaac, 2005; McFarquhar et al., 2007; Heymsfield, 2007; Vidaurre and Hallett, 2009; Jensen et al., 2009; Korolev et al., 2010). Ice particles shatter and break for two reasons. The first is related to the mechanical impact of the ice crystals with the probes' housing that happens upstream of the sample volume as ice crystals break into small fragments that get entrained in air passing through the sample volume. The second is due to particle fragmentation related to stresses experienced by an ice particle caused by the velocity shear and vorticity generated by the probe housing. The first type of shattering may affect nearly all type of ice particles, whereas the second type of shattering mainly affects aggregates with weak bonding between ice particles (e.g. aggregates of dendrites or needles) or some types of naturally fragile ice particles (e.g. bullet rosettes, dendrites).

The fragments from mechanical shattering have much smaller sizes and the number of the pieces in the view field of OAPs may exceed a few hundred. The analysis of 2D imagery registered by the imaging probes suggests that the frequency of occurrence of the first type of shattering is significantly more common than of the second. The analysis of high speed videos recorded in wind tunnels indicate that after shattering the ice particle fragments may travel several centimeters across the wind direction before they align with the airflow. The shattered fragments have different sizes, velocities and trajectories at the initial moment after the impact.

Based on the analysis of data collected during the wind tunnel experiments and in-situ measurements, our current knowledge about shattering of ice particles can be summarized as follows:

1. Ice particles bouncing from the surface of cloud probes may travel up to 5-6 cm across the airflow at $100 \mathrm{~m} / \mathrm{s}$ and $1000 \mathrm{mb}$ pressure before passing through the sample area. For the same conditions ice particles may bounce forward against the airflow up to $1 \mathrm{~cm}$.

2. After impact with a solid surface, ice particles may shatter into small fragments. At aircraft speeds, the size of particle fragments has been observed to be as small as $5 \mu \mathrm{m}$.

3. The number of fragments per shattered particle may reach the order of $10^{3}$, depending on the particle size and habit. The number of fragments that intersect the sample volume of the particle imaging probes may reach a few hundred per shattered particle.

4. Shattered particles often form a cluster of closely spaced fragments with characteristic dimensions several centimeters along the airflow direction in the vicinity of the probe's sample volume.

5. The concentration of large particles is not noticeably affected by shattering.

6. Some correction for the effects of particle shattering, based on particle inter-arrival times (Cooper, 1977; Field et al., 2006) and the filtering out of fragmented images (Korolev and Isaac, 2005) are possible.
7. One way to mitigate shattering is to minimize the offending surface area. The modified tips should deflect bouncing particles and shedding water away from the sample volume and optical field apertures. Work has been done to develop such tips (Korolev et al., 2010). Comparisons of simultaneous measurements by OAPs with and without modified tips have shown that the modification can effectively mitigate the shattering effect (Korolev et al., 2010).

\section{Summary}

The preceding discussion of measurement capabilities for aerosol, cloud and radiation was designed to broadly orient the reader to the instrumentation that is currently available for airborne applications and to introduce some emerging technologies that show promise, especially with respect to addressing a number of measurement challenges that are barriers to advancing our understanding of aerosols and clouds and their impact on radiation and climate.

It is essential that atmospheric scientists, students, instrument developers, vendors and aircraft operators understand the pros and cons of the instruments with which they are involved, whose data they evaluate and whose limitations they may wish to resolve. Significant progress has been made since airborne research was begun but there are significant gaps in our understanding of atmospheric processes that require better measurements that can only be made from aircraft with better instrumentation.

The book "Airborne Measurements-Methods and Instruments", to be published in mid-2012 by Wiley, from which this presentation was extracted, will cover in much greater detail, not only measurements of aerosol, cloud and radiation measurement, but also measurements of basic thermodynamic and dynamic parameters and gas phase constituents. In addition there is a much more comprehensive chapter on particle sampling issues and chapters on hyperspectral and active remote sensing.

\section{Disclaimer}

The mentioning of a particular commercial vendor or product in this paper does not constitute endorsement of the either the vendor or the product.

\section{Acknowledgments}

The authors would like to thank the European Facility for Airborne Research (EUFAR) who is providing support for all the chapter leaders of the upcoming reference book on airborne measurements. Numerous people have made contributions to this book and many of these contributions are included in this review article as well. In particular we would like to thank Alexander Kokhanovsky, Jacob Fugal, Raymond Shaw, Paul Lawson, Patrick Chuang, William Bachalo and Biagio Esposito. Finally, we would like to express our deep appreciation to the two anonymous reviewers who painstakingly read through the manuscript and made numerous suggestions that greatly improved the paper. 


\section{References}

Albrecht, H.-E., et al., 2003. Laser Doppler and Phase Doppler Measurement Techniques. Springer-Verlag.

Anderson, T.L., Ogren, J.A., 1998. Determining aerosol radiative properties using the TSI 3563 integrating nephelometer. Aerosol Sci. Technol. 29, 57-69.

Arnott, W.P., et al., 1994. Role of small ice crystals in radiative properties of cirrus: a case study, FIRE II, November 22 1991. J. Geophys. Res. 99, D1. doi:10.1029/93JD02781.

Arnott, W.P., et al., 1995. Direct airborne sampling of small ice crystals and the concentration and phase of haze particles. paper presented at the 9th Symposium on Meteorological Observations and Instrumentation: Published by American Meteorol. Soc. Charlotte, N. C.

Arnott, W.P., et al., 1999. Photoacoustic spectrometer for measuring light absorption by aerosols: instrument description. Atmos. Environ. 33, 2845-2852.

Azzopardi, B.J., 1979. Measurement of drop sizes. Int. J. Heat Mass Transfer. $22,1245-1279$

Bachalo, W.D., 1980. A method for measuring the size and velocity of spheres by dual beam light scatter interferometry. Appl. Opt. 19.

Bachalo, W.D., 1994. Experimental methods in multiphase flows. Int. J. Multiphase Flow 20, 261-295 Suppl.

Bachalo, W.D., Houser, M.J., 1984. Phase Doppler spray analyzer for simultaneous measurements of drop size and velocity distributions. Opt. Eng. 23.

Bahreini, R., et al., 2003. Aircraft-based aerosol size and composition measurements during ACE-Asia using an Aerodyne aerosol mass spectrometer. J. Geophys. Res. 108, D23.

Baron, P.A., Willeke, K., 2005. Aerosol Measurement, Principles, Techniques and Applications, 2nd Ed. John Wiley and Sons, New York. 1160 pp.

Baumgardner, D., 1983. An analysis and comparison of five water droplet measuring instruments. J. Appl. Meteor. 22, 891-910.

Baumgardner, D., Rodi, A., 1989. Laboratory and wind tunnel evaluations of the Rosemount icing detector. J. Atmos. Ocean. Technol. 6, 971-979.

Baumgardner, D., et al., 1992. Interpretation of measurements made by the FSSP-300X during the Airborne Arctic Stratospheric Expedition. J. Geophys. Res. 97, 8035-8046.

Baumgardner, D., et al., 2001. The cloud, aerosol and precipitation spectrometer (CAPS): a new instrument for cloud investigations. Atmos. Res. 59-60, 251-264.

Baumgardner, D., et al., 2002. Clouds: measurement techniques in-situ. In: Curry, J., Holton, J., Pyle, J. (Eds.), Encyclopaedia of Atmospheric Science. Academic Press, U.K. ISBN: 0-12-227090-8.

Baumgardner, D., et al., 2004. Warming of the Arctic lower stratosphere by light absorbing particles. Geophys. Res. Lett. 31.

Baumgardner, D., et al., 2005. The shapes of very small cirrus particles derived from in situ measurements. Geophys. Res. Lett. 32, L01806. doi:10.1029/2004GL021300.

Beuttell, R.G., Brewer, A.W., 1949. Instruments for the measurement of the visual range. J. Sci. Instrum. 26, 357-359.

Biter, C.J., et al., 1987. The drop response of the CSIRO liquid water content. J. Atmos. Ocean. Technol. 4, 359-367.

Blackwell, W. et al, 2001. NPOESS Aircraft Sounder Testbed-Microwave (NAST-M): instrument description and initial flight results. IEEE Trans. Geosci. Remote Sens. 39, 2444-2453.

Blomquist, B.W., et al., 2001. An evaluation of the community aerosol inlet for the NCAR C-130 research aircraft. J. Atmos. Oceanic Technol. 18, 1387-1397.

Borrmann, S., Jaenicke, R., 1993. Application of microholography for groundbased in situ measurements in stratus cloud layers: a case study. J. Atmos. Ocean. Technol. 10, 277-293.

Borrmann, S, et al, 2000. Application of the T-matrix method to the measurement of aspherical (ellipsoidal) particles with forward scattering optical particle counters. J. Aerosol Sci. 31, 789-799.

Brown, P.R.A., 1989. Use of holography for airborne cloud physics measurements. J Atmos. Ocean. Technol. 6, 293-306.

Bucholtz, A., et al., 2008. The Stabilized Radiometer Platform (STRAP)-an actively stabilized horizontally level platform for improved aircraft irradiance measurements. J. Atmos. Ocean. Technol. 25, 2161-2175. doi:10.1175/ 2008JTECHA1085.1.

Buehler, S., et al., 2007. A concept for a satellite mission to measure cloud ice water path, ice particle size, and cloud altitude. Quart. J. Roy. Meteor. Soc. 133 109-128.

Bundke, U., et al., 2008. The Fast Ice Nucleus Chamber FINCH. Atmos. Res. 90, 180-186.

Bundke, U., et al., 2010. Development of a Bioaerosol single particle detector (BIO IN) for the Fast Ice Nucleus CHamber FINCH. Atmos. Meas. Technol. 3, 1-9.

Cain, S.A., et al., 1998. Qualitative and quantitative wind tunnel measurements of the airflow through a shrouded airborne aerosol sampling probe. J. Aerosol Sci. 29, 1157-1169.
Canagaratna, M.R., et al., 2007. Chemical and microphysical characterization of ambient aerosols with the aerodyne aerosol mass spectrometer. Mass Spectrom. Rev. 26, 185-222.

Cess, R., et al., 1995. Absorption of solar radiation by clouds: observations versus models. Science 267, 496-499.

Chandra, S., McFarland, A.R., 1997. Shrouded probe performance: variable flow operation and effect of free stream turbulence. Aerosol Sci. Technol. 26, 111-126.

Chuang, P.Y., et al., 2008. Airborne phase Doppler interferometry for cloud microphysical measurements. Aerosol Sci. Technol. 42, 685-703 2008.

Cober, S.G., et al., 2001a. Assessing cloud-phase conditions. J. Appl. Meteor. 40, 1967-1983.

Cober, S.G., et al., 2001b. Assessing the Rosemount icing detector with in situ measurements. J. Atmos. Ocean. Technol. 18, 515-528.

Cohen, R.D., 1991. Shattering of a liquid drop due to impact. Proc. Roy. Soc. Lond. A 435, 483-503.

Cooper, W.A., 1977. Cloud physics investigation by the University of Wyoming in HIPLEX 1977. Bur. Reclam. Rep. AS 119321 pp.

Cotton, R., et al., 2009. The ability of the small ice detector (SID-2) to characterize cloud particle and aerosol morphologies obtained during flights of the FAAM BAe-146 research aircraft. J. Atmos. Ocean. Technol. 27, 290-303.

Crépel, O., et al., 1997. A new airborne Polar Nephelometer for the measurements of optical and microphysical cloud properties. Part II: Preliminary tests. Ann. Geophys. 15, 460-470.

Crewell, S., et al., 1994. Comparison of $\mathrm{ClO}$ measurements by airborne and spaceborne microwave radiometers in the arctic winter stratosphere 1993. Geophys. Res. Lett. 22, 1489-1492.

Cziczo, D.J., et al., 2001. Ablation, flux, and atmospheric implications of meteors inferred from stratospheric aerosol. Science 291, 1772-1775.

Cziczo, D.J., et al., 2003. A method for single particle mass spectroscopy of ice nuclei. Aer. Sci. Technol. 37, 460-470.

Davis, A.B., et al., 1999. Horizontal structure of marine boundary-layer clouds from $\mathrm{cm}$ to $\mathrm{km}$ scales. J. Geophys. Res. 104, 6123-6144.

Davis, S.M., et al., 2007. Measurement of total water with a tunable diode laser hygrometer: inlet analysis, calibration procedure, and ice water content determination. J. Atmos. Ocean. Technol. 24, 463-475.

DeCarlo, P.F., et al., 2008. Fast airborne aerosol size and chemistry measurements above Mexico City and Central Mexico during the MILAGRO campaign. Atmos. Chem. Phys. 8, 4027-4048.

Delene, D.J., et al., 1998. A balloon-borne cloud condensation nuclei counter. J. Geophys. Res. 103, 8927-8934.

DeMott, P.J., et al., in press. Resurgence in ice nucleation research. Bull. Amer. Meteor. Soc.

Von der Weiden, et al., 2009. Particle Loss Calculator-a new software tool for the assessment of the performance of aerosol inlet system. Atmos. Meas. Technol. 2, 479-494.

Dhaniyala, S., et al., 2003. Novel aerosol/gas inlet for aircraft-based measurements. Aerosol Sci. Technol. 37, 828-840.

Dibb, J.E., et al., 2002. Airborne sampling of aerosol particles: comparison between surface sampling at Christmas Island and P-3 sampling during PEM-Tropics. B. J. Geophy. Res. 108.

Dibb, J.E., et al., 2003. Aerosol chemical composition in Asian continental outflow during the TRACE-P campaign: comparison with PEM-West. B. J. of Geophys. Res. 108

Dubovik, O., 2004. Optimization of numerical inversion in photopolarimetric remote sensing. In: Videen, G., Yatskiv, Y., Mishchenko, M. (Eds.), Photopolarimetry in Remote Sensing. Kluwer Academic Publishers, Dordrecht, Netherlands, pp. 65-106.

Durst, F., et al., 1981. Principle and Practice of Laser-Doppler Anemometry. Academic Press, London.

Eddy, P., et al., 2006. Subisokinetic sampling characteristics of high speed aircraft inlets: a new CFD-based correlation considering inlet geometries. J. Aerosol Sci. 37, 1853-1870.

Emery, E., et al., 2004. Ice Particle Impact on Cloud Water Content Instrumentation. 42nd AIAA Aerospace Sciences Meeting and Exhibit, Jan. 2004, AIAA-2004-0731.

Field, P.R., et al., 2003. Ice particle interarrival times measured with a fast FSSP. J. Atmos. Ocean. Technol. 20, 249-261.

Field, P.R., et al., 2006. Shattering and particle interarrival times measured by optical array probes in ice clouds. J. Atmos. Ocean. Technnol. 23, 1357-1370.

Froyd, K.D., et al., 2009. Aerosol composition of the tropical upper troposphere. Atmos. Chem. Phys. 9, 4363-4385.

Fugal, J.P., Shaw, R.A., 2009. Cloud particle size distributions measured with an airborne digital in-line holographic instrument. Atmos. Meas. Technol. 2, 259-271.

Fugal, J.P., et al., 2004. Airborne digital holographic system for cloud particle measurements. Appl. Opt. 43, 5987-5995. 
Fugal, J.P., et al., 2009. Practical methods for automated reconstruction and characterization of particles in digital in-line holograms. Meas. Sci. Technol. 20, 075501. doi:10.1088/0957-0233/20/7/075501.

Fukuta, N., Saxena, V.K., 1979. A horizontal thermal gradient cloud condensation nucleus spectrometer. J. Appl. Meteor. 18, 1352-1362.

Gardiner, B.A., Hallett, J., 1985. Degradation of in-cloud forward scattering spectrometer probe measurements in the presence of ice particles. J. Atmos. Ocean. Technol. 2, 171-180.

Garrett, T.J., 2007. Comment on "Effective radius of ice cloud particle populations derived from aircraft probes" by Heymsfield et al. J. Atmos. Ocean. Technol. 24, 1495-1503. doi:10.1175/JTECH2075.1.

Garrett, T.J., 2008. Observational quantification of the optical properties of cirrus cloud. Light Scattering Reviews, v. 3. Springer-Praxis, Berlin.

Garrett, T.J., et al., 2001. Shortwave, single-scattering properties of arctic ice clouds. J. Geophys. Res. 106, 15,155-15,172.

Gayet, J.-F., et al., 1996. The reliability of the PMS FSSP in the presence of small ice crystals. J. Atmos. Ocean. Technol. 13, 1300-1310.

Gayet, J.-F., et al., 1997. A new airborne Polar Nephelometer for the measurements of optical and microphysical cloud properties. Part I: Theoretical design. Ann. Geophys. 15, 451-459.

Gayet, J.-F., et al., 1998. In situ measurements of the scattering phase function of stratocumulus, contrails and cirrus. Geophys. Res. Lett. 25, 971-974.

Gerber, H., 1991. Direct measurement of suspended particulate volume concentration and far-infrared extinction coefficient with a laserdiffraction instrument. Appl. Opt. 30, 4824-4831.

Gerber, H., 1998. Standards for measuring fog liquid water content. In: Schemenauer, R.S., Bridgman, H. (Eds.), Proc. 1st Intern. Conf. On Fog and Fog Collection, pp. 1-4. QC929.F7157.

Gerber, H., et al., 2000. Nephelometer measurements of the asymmetry parameter, volume extinction coefficient and backscatter ratio in Arctic clouds. J. Atmos. Sci. 57, 3021-3034.

Gerber, H., et al., 2004. Nephelometer measurements in Florida thunderstorms. Proc. 14th Int. Conf. On Clouds and Precip., 19-23 July, Bologna, Italy, pp. 1092-1094.

Gerber, H., Frick, G., Malinowski, S.P., Brenguier, J.-L., Burnet, F., 2005. Holes and entrainment in stratocumulus. J. Atmos. Sci. 62, 443-459.

Gerber, H., Frick, G., Jensen, J.B., Hudson, J.G., 2008. Entrainment, mixing, and microphysics in trade-wind cumulus. J. Meteor. Soc. Japan 86A, 87-106.

Gonda, R., Takahashi, T., 1984. Initial growth forms of snow crystals growing from frozen droplets. J Meteor. Soc. Japan 62, 190-192.

Hallett, J., et al., 1998. A technique for characterizing aerosol and cloud particles by real time processing. Proceedings of an International Specialty Conference, Long Beach, California, vol. 1. Air \& Waste Manage. Assoc, Pittsburgh, Pa, pp. 318-325.

Hegg, D.A., et al., 2005. Determination of the transmission efficiency of an aircraft aerosol inlet. Aerosol Sci. Technol. 39, 966-971. doi:10.1080/ 02786820500377814.

Heintzenberg, J., et al., 2006. Intercomparisons and aerosol calibrations of 12 commercial integrating nephelometers of three manufacturers. J. Atmos. Oceanic Technol. 23, 902-914.

Hendricks, J., et al., 2004. Simulating the global atmospheric black carbon cycle: a revisit to the contribution of aircraft emissions. Atmos. Chem. Phys. 4, 2521-2541.

Hermann, M., et al., 2001. Sampling characteristics of an aircraft-borne aerosol inlet system. J. Atmos Oceanic Technol. 18, 7-19.

Heymsfield, A.J., 2007. On measurements of small ice particles in clouds. Geoph. Res. Lett. 34, L23812. doi:10.1029/2007GL030951.

Heymsfield, A.J., et al., 2010. Aircraft-induced hole punch and canal clouds: inadvertent cloud seeding. Bull. Amer. Meteor. Soc. in press. doi: 10.1175/2009BAMS2905.1.

Heymsfield, A.J., McFarquhar, G.M., 1996. High albedos of cirrus in the tropical Pacific warm pool: microphysical interpretations from CEPEX and from Kwajalein, Marshall Islands. J. Atmos. Sci. 53, 2424-2451.

Heymsfield, A.J., Miloshevich, L.M., 1989. Evaluation of liquid water measuring instruments in cold cloud sampled during FIRE. J. Atmos. Ocean. Technol. 6, 378-388.

Hinds, W.C., 1999. Aerosol Technology, Properties, Behavior and Measurement of Airborne Particles, 2nd Ed. JohnWiley and Sons, New York. 504 pp.

Hirleman, E.D., et al., 1984. Response characteristics of laser diffraction particle size analyzers: optical volume extent and lens effects. Opt. Eng. $23,610-619$.

Hirst, E., et al., 2001. Discrimination of micrometre-sized ice and supercooled droplets in mixed phase clouds. Atmos. Environ. 35, 33-47.

Hofzumahaus, A., 2006. Measurement of photolysis frequencies in the atmosphere. Analytical Techniques for Atmospheric Measurement. Blackwell Publishing, pp. 406-500.

Hofzumahaus, A., et al., 2002. Solar actinic radiation $(280-420 \mathrm{~nm})$ in the cloud-free troposphere between ground and $12 \mathrm{~km}$ altitude: measure- ments and model results. J. Geophys. Res. 107. doi:10.1029/2001JD900 142.

Hudson, J.G., 1989. An instantaneous CCN spectrometer. J. Atmos. Ocean. Technol. 6, 1055-1065.

Hudson, J.G., Squires, P., 1976. An improved continuous flow diffusion cloud chamber. J. Appl. Meteor. 15 (776), 782.

Huebert, B.J., et al., 1990. Airborne aerosol inlet passing efficiency measurements. J. Geophys. Res. 95, 16369-16381.

Huebert, B.J., et al., 2004. PELTI: Measuring the passing efficiency of an airborne low turbulence aerosol inlet. Aerosol Sci. Technol. 38, 803-826.

Ide, Robert F., 1999. Comparison of liquid water content measurement techniques in an icing wind tunnel. NASA Technol. Mem. TM-1999209643; ARL-TR-2134. 24 pp.

Ide, Robert F., Oldenburg, J.R., 2001. Icing cloud calibration of the NASA Glenn Icing Research Tunnel. 39th Aerospace Sciences Meeting and Exhibit, AIAA-2001-0234. Jan. 2001.

Irshad, H., et al., 2004. Wind tunnel evaluation of an aircraft-borne sampling system. Aerosol Sci. Technol. 38, 311-321.

Isaac, G.A., et al., 2006. Assessing the collection efficiency of natural cloud particles impacting the Nevzorov total water content probe. 44th AIAA Aerospace Sciences Meeting and Exhibit, 9-12 Jan. 2006, Reno, NV, AIAA2006-1221.

Jäkel, E., et al., 2005. Airborne system for fast measurements of upwelling and downwelling spectral actinic flux densities. Appl. Opt. 44, 434-444.

Jayne, J.T., et al., 2000. Development of an aerosol mass spectrometer for size and composition analysis of submicron particles. Aer. Sci. Technol. 33, 49-70.

Jensen, E.J., et al., 2009. On the importance of small ice crystals in tropical anvil cirrus. Atmos. Chem. Phys. 9, 5519-5537.

King, W.D., Turvery, D.E., 1986. A thermal device for aircraft measurement of the solid water content of clouds. J. Atmos. Ocean. Technol. 3, 356-362.

King, W.D., et al., 1978. A hot-wire water device having fully calculable response characteristics. J. Appl. Meteor. 17, 1809-1813.

King, W.D., et al., 1985. Icing wind tunnel tests on the CSIRO liquid water probe. J. Atmos. Ocean. Technol. 2, 340-352.

Knollenberg, R.G., 1970. The Optical Array: an alternative to scattering or extinction for airborne particle size determination. J. Appl. Meteor. 9 86-103.

Knollenberg, R.G., 1976. Three new instruments for cloud physics measurements: the 2-D spectrometer probe, the forward scattering spectrometer probe and the active scattering aerosol spectrometer. Amer. Met. Soc. Int'l Conf. Cloud Phys. 554-561.

Knollenberg, R.G., 1981. In: Hobbs, P.V., Deepak, A. (Eds.), Techniques for probing cloud microstructure. Clouds, Their Formation, Optical Properties and Effects. Academic Press. 495 pp.

Korolev, A.V., Isaac, G.A., 2005. Shattering during sampling by OAPs and HVPS. Part 1: Snow particles. J. Atmos. Ocean Technol. 22, 528-542.

Korolev, A.V., et al., 1998. The Nevzorov Airborne Hot-wire LWC-TWC Probe: principle of operation and performance characteristics. J. Atmos. Ocean. Technol. 15, 1495-1510.

Korolev, A.V., Isaac, G., Mazin, I., Barker, H., 2001. Microphysical properties of continental stratiform clouds. Quart. J. Roy. Meteor. Soc. 127, 2117-2151.

Korolev, A.V., et al., 2008. Improved Airborne Hot-Wire Measurements of Ice Water Content in Clouds. 15th Intl. Conf. on Cloud and Precipitation, Cancun, Mexico, 7-11 July 2008.

Korolev, A.V., et al., 2010. Small ice particle observations in tropospheric clouds: fact or artifact? Airborne Icing Instrumentation Evaluation Experiment. Bull. Amer. Meteor. Soc.ftp://depot.cmc.ec.gc.ca/upload/ hsvideo available from.

Kozikowska, A., et al., 1984. Preliminary results of an investigation of the spatial distribution of fog droplets by a holographic method. Quart. J. Roy. Meteor. Soc. 110, 65-73.

Krämer, M., Afchine, A., 2004. Sampling characteristics of inlets operated at low U/Uo ratios: new insights from computational fluid dynamics (CFX) modeling. J. Aerosol Sci. 35, 683-694.

Kreidenweis, S.M., et al., 1998. Isolating and identifying atmospheric icenucleating aerosols: a new technique. Atmos. Res. 46, 263-278.

Kyle, T.G., 1975. The measurement of water content by an evaporator. J. Appl. Meteor. 14, 327-332.

Lala, G.G., Juisto, J.E., 1977. An automatic light scattering CCN counter. J. Appl. Meteor. 16, 413-418.

Lawson, R.P., Cormack, R.H., 1995. Theoretical design and preliminary tests of two new particle spectrometers for cloud microphysics research. Atmos. Res. 35, 315-348.

Lawson, R.P., et al., 2006. The 2D-S (Stereo) probe: design and preliminary tests of a new airborne, high speed, high-resolution particle imaging probe. J. Atmos. Ocean. Technol. 23, 1462-1477.

Lilie, L., et al., 2004. A Multiwire Hot-Wire Device for Measurement of Icing Severity, Total Water Content, Liquid Water Content, and Droplet Diameter. 43rd AIAA Aerospace Sciences Meeting, Reno, Nevada, 11-13 January 2005, AIAA-2005-0860. 
Liu, P.S.K., et al., 1992. The response of the Particle Measuring Systems airborne ASAP and PCASP to $\mathrm{NaCl}$ and latex particles. Aerosol Sci. Technol. 16, 83-95.

Lobl, E., et al., 2007. An AMSR precipitation validation campaign. Bull. Amer. Meteor. Soc. 88, 551-558.

Lu, J., et al., 2008. Lagrangian particle tracking in three dimensions via singlecamera in-line digital holography. New J. Phys. 10, 125015. doi:10.1088/ $1367-2630 / 10 / 12 / 125013$.

Mazin, I.P., et al., 2001. Thermodynamics of icing cylinder for measurements of liquid water content in super cooled clouds. J. Atmos. Ocean. Technol. $18,543-558$.

McFarquhar, G.M., et al., 2007. The importance of small ice crystals to cirrus properties: observations from the Tropical Warm Pool International cloud Experiment (TWP-ICE). Geophys. Res. Lett. 57, L13803. doi:10.1029/2007GL029 865.

McMurry, P.H., 2000. The history of condensation nucleus counters. Aerosol Sci. Technol. 33, 297-322.

Merceret, F.J., Schricker, T.L., 1975. A new hot-wire liquid water meter J. Appl. Meteor. 14, 319-326.

Mie, G., 1908. Beiträge zur Optik trüber Medien, speziell kolloidaler Metallösungen. Ann. Phys. 25, 377-445.

Moore, R.H., Nenes, A., 2009. A scanning flow CCN analysis-a method for fast measurements of CCN spectra. Aer. Sci. Technol. 43, 1192-1207.

Moore II, K.G., et al., 2004. A comparison of similar aerosol measurements made on the NASA P3-B, DC-8, and NSF C-130 aircraft during TRACE-P and ACEAsia. J. Geophys. Res. 109 No. D15, D15S15 10.1029/2003JD003543.

Moosmüller, H., et al., 2009. Aerosol light absorption and its measurement: a review. J. Quant. Spectr. Rad. Trans. 110, 844-878.

Morgan, W.T., et al., 2009. Vertical distribution of sub-micron aerosol chemical composition from North-Western Europe and the North-East Atlantic. Atmos. Chem. Phys. 9, 5389-5401.

Moteki, N., et al., 2007. Evolution of mixing state of black carbon particles: aircraft measurements over the western Pacific in March 2004. Geophys. Res. Lett. 34.

Murphy, D.M., 2007. The design of single particle mass spectrometers. Mass Spectrom. Rev. 26, 150-165.

Murphy, D.M., Schein, M.E., 1998. Wind tunnel tests of a shrouded aircraft inlet. Aerosol Sci. Technol. 28, 33-39.

Murphy, D.M., et al., 1998. In situ measurements of organics, meteoritic material, mercury, and other elements in aerosols at 5 to 19 kilometers. Science 282, 1664-1669.

Murphy, D.M., et al., 2006. Single-particle mass spectrometry of tropospheric aerosol particles. J. Geophys. Res. 111.

Neel, C.B., 1955. A heated-wire liquid-water-content instrument and results of initial flight tests in icing conditions. NASA Research Memo., RM A54123, $33 \mathrm{pp}$.

Nenes, A., et al., 2001. Kinetic limitations on cloud droplet formation and impact on cloud albedo. Tellus Ser. B 53, 133-149.

Nevzorov, A.N., 1980. Aircraft cloud water content meter. Comm. a la 8eme conf int. sur la phys. des nuages, v. II. Clermont-Ferrand, France, pp. 701-703.

Nicholls, S., et al., 1990. A new fast response instrument for measuring total water content from aircraft. J. Atmos. Ocean. Technol. 7, 706-718.

Noone, K.J., et al., 1988. Design and calibration of a counterflow virtua impactor for sampling of atmospheric fog and cloud droplets. Aerosol Sci. Technol. 8, 235-244.

Noone, K.B., et al., 1993. In situ observations using the counterflow virtual impactor. J. Atmos. Ocean. Technol. 10, 294-303.

Orsini, D.A., et al., 2003. Refinements to the particle-into-liquid sampler (PILS) for ground and airborne measurements of water soluble aerosol composition. Atmos. Environ. 37, 1243-1259.

Petzold, A., Schönlinner, M., 2004. Multi-angle absorption photometry-a new method for the measurement of aerosol light absorption and atmospheric black carbon. J. Aerosol Sci. 35, 421-441.

Petzold, A., et al., 2005. Evaluation of multiangle absorption photometry for measuring aerosol light absorption. Aerosol Sci. Technol. 39, 40-51.

Pilewskie, P., et al., 2003. Solar spectral radiative forcing during the Southern African Regional Science Initiative. J. Geophys. Res. 108. doi:10.1029/ 2002JD002 411

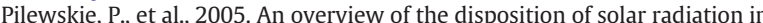
the lower atmosphere: connections to the SORCE mission and climate change. Sol. Phys. 230, 55-69.

Porter, J.N., et al., 1992. Aircraft studies of size dependent aerosol sampling through inlets. J. Geophys. Res. 97, 3815-3824.

Pratt, K.A., et al., 2009a. In situ detection of biological particles in cloud icecrystals. Nat. Geosci. 2, 397-400.

Pratt, K.A., et al., 2009b. Development and characterization of an aircraft aerosol time-of-flight mass spectrometer. Anal. Chem. 81, 1792-1800.

$\mathrm{Pu}$, S.L., et al., 2005. Particle field characterization by digital in-line holography: 3D location and sizing. Exp. Fluids 39, 1-9.
Rahman, A.A., et al., 2006. Integrating nephelometer with a low truncation angle and an extended calibration scheme. Meas. Sci. Technol. 17, 1723-1732.

Ram, M., et al., 1995. Design of a shrouded probe for airborne aerosol sampling in a high velocity airstream. J. Aerosol Sci. 26, 945-962.

Ranz, W., Wong, J.B., 1952. Jet impactors for determining the particle size distribution of aerosols. Arch Ind. Hyg. Occ. Med. 5, 464-477.

Raupach, S.M.F., 2009. Cascaded adaptive-mask algorithm for twin-image removal and its application to digital holograms of ice crystals. Appl. Opt. 42, 287-301.

Raupach, S.M.F., et al., 2006. Digital crossed-beam holography for in situ imaging of atmospheric particles. J. Opt. Pure Appl. Opt. 8, 796-806.

Roberts, G., Nenes, A., 2005. A continuous-flow streamwise thermal-gradient CCN chamber for atmospheric measurements. Aer. Sci. Technnol. 39, 206-221.

Rogers, D.C., 1988. Development of a continuous flow thermal gradient diffusion chamber for ice nucleation studies. Atmos. Res. 22, 149-181.

Rogers, D.C., et al., 2001. A continuous-flow diffusion chamber for airborne measurements of ice nuclei. J. Atmos. Oceanic Technol. 18, 725-741.

Rose, D., et al., 2008. Calibration and measurement uncertainties of a continuous-flow cloud condensation nuclei counter (DMT-CCNC): CCN activation of ammonium sulfate and sodium chloride aerosol particles in theory and experiment. Atmos. Chem. Phys. 8, 1153-1179.

Ruskin, R.E., 1965. Measurements of water-ice budget changes at $-5 \mathrm{C}$ in AgI seeded tropical cumulus. J. Appl. Meteor. 6, 72-81.

Scheuer, E., et al., 2003. Seasonal distributions of fine aerosol sulfate in the North American Arctic basin during TOPSE. J. Geophys. Res. 108, 8370.

Schiller, C., et al., 2008. The ice water content of Arctic, midlatitude and tropical cirrus. J. Geophys. Res. 113, D24208. doi:10.1029/ 2008JD010342.

Schmitt, C.G., Heymsfield, A.J., 2009. The size distribution and mass-weighted terminal velocity of low-latitude tropopause cirrus crystal populations. J. Atmos. Sci. 66, 2013-2028.

Schwarz, J.P., et al., 2006. Single-particle measurements of midlatitude black carbon and light-scattering aerosols from the boundary layer to the lower stratosphere. J. Geophys. Res. 111, D16.

Shetter, R., Müller, M., 1999. Photolysis frequency measurements using actinic flux spectroradiometry during the PEM-Tropics mission: instrumentation description and some results. J. Geophys. Res. 104, 5647-5661.

Shetter, R., et al., 2003. Comparison of airborne measured and calculated spectral actinic flux and derived photolysis frequencies during the PEM Tropics B mission. J. Geophys. Res. 108. doi:10.1029/2001JD001 320.

Sinnerwalla, A.M., Alofs, D.J., 1973. A cloud nucleus counter with long available growth time. J. Appl. Meteor. 12, 831-835.

Small, J.D., Chuang, P.Y., 2008. New observations of precipitation initiation in warm cumulus clouds. J. Atmos. Sci. 65, 2972-2982.

Snider, J.R., Brenguier, J.-L., 2000. A comparison of cloud condensation nuclei and cloud droplet measurements obtained during ACE-2. Tellus Ser. B 52, $828-842$.

Snider, J.R., et al., 2003. Aerosol activation in marine stratocumulus clouds: 2. Köhler and parcel theory closure studies. J. Geophys. Res. 108, 8629. doi:10.1029/2002JD002692.

Squires, P., Twomey, S., 1966. A comparison of cloud nucleus measurements over central North America and the Caribbean Sea. J. Atmos. Sci. 22, 401-404.

Stallabrass, J., 1978. An appraisal of the single rotating cylinder method of liquid water content measurement. Report LTR-LT-92. 26 pp., Published by National Research Council Canada.

Stephens, M., et al., 2003. Particle identification by laser-induced incandescence in a solid-state laser cavity. Appl. Opt. 42, 3726-3736.

Strapp, J.W., et al., 1992. Hydrated and dried aerosol-size-distribution measurements from the particle measuring systems FSSP-300 probe and the deiced PCASP-100X probe. J. Atmos. Oceanic Technol. 9, 548-555.

Strapp, J.W., et al., 2002. Wind tunnel measurements of the response of hotwire liquid water content instruments to large droplets. J. Atmos. Ocean. Technol. 20, 791-806.

Strapp, J.W., et al., 2005. Preliminary Comparison of Ice Water Content as Measured by Hot Wire Instruments of Varying Configuration. 43rd AIAA Aerospace Sciences Meeting, Reno, NV, 11-13 January 2005b, AIAA-20050860.

Strapp, J.W., et al., 2008. Calibration of Ice Water Content in a Wind Tunnel/ Engine Test Cell Facility. 15th Intl. Conf. on Cloud and Precipitation, Cancun, Mexico, 7-11 July 2008.

Super, A.B., et al., in press. Comparison of silver iodide outputs from two different generators and solutions measured by acoustic ice nucleus counters. J. Wea. Mod.

Thomson, D.S., et al., 2000. Particle analysis by laser mass spectrometry WB-57F instrument overview. Aerosol Sci. Technol. 33, 153-169. 
Trolinger, J.D., 1975. Particle field holography. Opt. Eng. 14, 383-392.

Twohy, C.H., 1998. Model calculations and wind tunnel testing of an isokinetic shroud for high-speed sampling. Aerosol Sci. Technol. 29, 261-280.

Twohy, C.H., et al., 1997. Measurement of condensed water content in liquid and ice clouds using an airborne counterflow virtual impactor. J. Atmos. Ocean. Technol. 14, 197-202.

Twohy, C.H., et al., 2003. Performance of a counterflow virtual impactor in the NASA Icing Research Tunnel. J. Atmos. Ocean. Technol. 20, 781-790.

Twomey, S., Wojciechowski, T.A., 1969. Observations of the geographic variations of cloud nuclei. J. Atmos. Sci. 26, 684-688.

Uhlig, E., et al., 1998. Holographic in-situ measurements of the spatial droplet distribution in stratiform clouds. Tellus 50B, 377-387.

Vay, S.A., et al., 2003. An assessment of aircraft-generated contamination on in situ trace gas measurements: determinations from empirical data acquired aloft. J. Atmos. Ocean. Technol. 20, 1478-1487.

Vidaurre, G., Hallett, J., 2007. Particle impact and breakup in aircraft measurements. J. Atmos. Oceanic Technol. 26, 972-983. doi:10.1175/ 2008JTECHA1147.1.

Vidaurre, G., Hallett, J., 2009. Ice and water content of stratiform mixed phase cloud. Q. J. R. Meteorol. Soc. 135, 1292-1306.

Vincent, J.H., 2007. Aerosol Sampling-Science, Standards, Instrumentation and Applications. John Wiley and Sons, New York. 636 pp.

Volz-Thomas, A., et al., 1996. Airborne measurements of the photolysis of NO2. J. Geophys. Res. 101, 18 613-18 627.

Weber, R.J., et al., 1998. Spurious aerosol measurements when sampling from aircraft in the vicinity of clouds. J. Geophys. Res. 103, 28337-28346.

Weber, R.J., et al., 1999. Intercomparison of airborne and surface-based measurements of condensation nuclei in the remote marine troposphere during ACE 1. J. Geophys. Res. 104, 21673-21683.

Weber, R.J., et al., 2001. A particle-into-liquid collector for rapid measurement of aerosol bulk chemical composition. Aer. Sci. Technol. 35, 718-727.

Weigel, R., et al., 2009. Experimental characterization of the COndensation PArticle counting System for high altitude aircraft-borne application. Atmos. Meas. Technol. 2, 243-258.

Weinstock, E.M., et al., 2006. Measurements of the total water content of cirrus clouds. Part I: Instrument details and calibration. J. Atmos. Ocean. Technol. 23, 1397-1409.

Wendisch, M., 1998. A quantitative comparison of ground-based FSSP and PVM measurements. J. Atmos. Ocean. Technol. 15, 887-900.

Wendisch, M., et al., 2001. An airborne spectral albedometer with active horizontal stabilization. J. Atmos. Ocean. Technol. 18, 1856-1866.

Wendisch, M., et al., 2002. Wind tunnel tests of the airborne PVM-100A response to large droplets. J. Atmos. Ocean. Technol. 19, 1577-1584.

Wendisch, M., et al., 2004. Meeting summary: aircraft particle inlets: stateof-the-art and future needs. Bull. Amer. Met. Soc. 85, 89-91.

Wilson, J.C., et al., 1983. The function and response of an improved stratospheric condensation nucleus counter. J. Geophys. Res. 88, 6781-6785

Wilson, J.C., et al., 2004. Function and performance of a low turbulence inlet for sampling supermicron particles from aircraft platforms. Aerosol Sci. Technol. 38 (790-802), 2004

Yarin, A.L., 2006. Drop impact dynamics: splashing, spreading, receding. Bouncing. Annu. Rev. Fluid Mech. 38, 159-192. doi:10.1146/annurev. fluid.38.050304.092144.

Zöger, M., et al., 1999. Fast in situ stratospheric hygrometers: a new family of balloonborne and airborne Lyman-a photofragment fluorescence hygrometers. J. Geophys. Res. 104, 1807-1816. doi:10.1029/1998JD100025.

\section{Acronyms}

AIDA: Aerosol Interaction and Dynamics in the Atmosphere

AMS: Aerosol Mass Spectrometer

AMSU: Advanced Microwave Sounding Unit

$B C$ : Black Carbon

CAS: Cloud and Aerosol Spectrometer

CAS-DPOL: CAS with Depolarization

$C C N$ : Cloud Condensation Nuclei

CDP: Cloud Droplet Probe

CEP: Cloud Extinction Probe

CFD: Computational Fluid Dynamics

CIN: Cloud Integrating Nephelometer

CIP: Cloud Imaging Probe

CIP-GS: CIP with Grayscale

$C N$ : Condensation Nuclei

CPC: Condensation Particle Counter

CPI: Cloud Particle Imager

CPSD: Cloud Particle Spectrometer with Depolarization

CSI: Cloud Spectrometer and Impactor

CVI: Counterflow Virtual Impactor

FISH: Fast In Situ Stratospheric Hygrometer

FOGS: Fiber Optic Gyros

FSSP: Forward Scattering Spectrometer Probe

GPS: Global Positioning System

HOLODEC: Holographic Detector for Clouds

HVPS: High Volume Particle Spectrometer

INS: Inertial Navigation System

IWC: Ice Water Content

LaMP: Laboratoire de Météorologie Physique

LWC: Liquid Water Content

MAAP: Multi-angle Absorption Photometer

MTP: Microwave Temperature Profiler

MVD: Median Volume Diameter

OAP: Optical Array Probe

OPC: Optical Particle Counter

PAS: Photoacoustic Spectrometer

PALMS: Particle Analysis by Laser Mass Spectrometer

PCASP: Passive Cavity Aerosol Spectrometer Probe

PDI: Phase Doppler Interferometer

PILS: Particle in Liquid Sampler

PIP: Precipitation Imaging Probe

PSA: Particle Surface Area

PSD: Particle Size Distribution

PVM: Particle Volume Monitor

$r B C$ : Refractory Black Carbon

SID: Small Ice Detector

SPARM: Stabilized Platform for Airborne Solar Radiation Measurements

SP2: Single Particle Soot Spectrometer

$S$ : Supersaturation

STRAP: Stabilized Radiometer Platform.

TDL: Tunable Diode Laser.

TOF: Time of Flight.

TWC: Total Water Content.

UHSAS: Ultrahigh Sensitivity Aerosol Spectrometer.

VIPS: Video Ice Particle Spectrometer.

2D-C: Two Dimensional cloud OAP.

2D-P: Two Dimensional precipitation OAP.

2D-S: Two dimensional stereo OAP.

260-X: One dimensional OAP. 